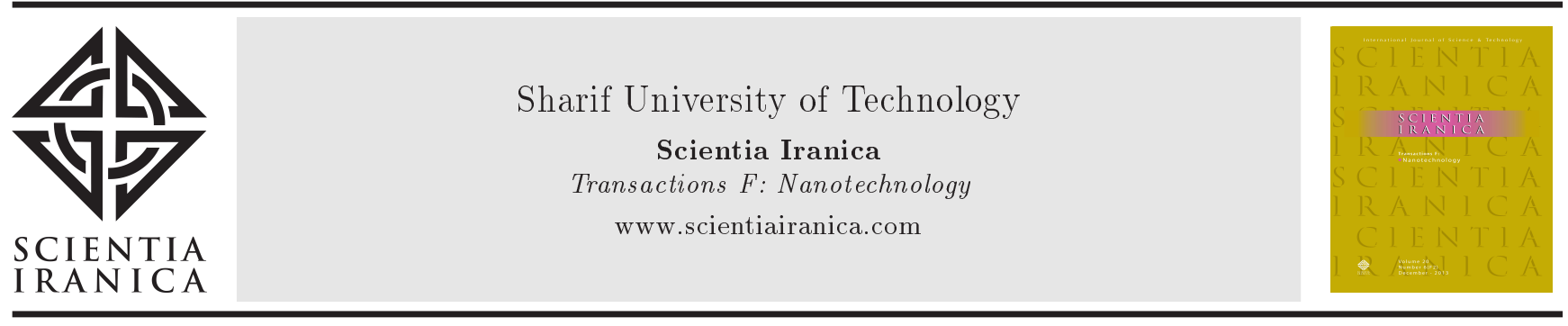

\title{
Second law analysis for radiative MHD slip flow of a nanofluid over a stretching sheet with non-uniform heat source effect
}

\author{
A.K. Abdul Hakeem ${ }^{\mathrm{a}, *}$, M. Govindaraju ${ }^{\mathrm{a}}$, B. Ganga ${ }^{\mathrm{b}}$ and M. Kayalvizhic \\ a. Department of Mathematics, Sri Ramakrishna Mission Vidhyalaya College of Arts and Science, Coimbatore - 641 020, India. \\ b. Department of Mathematics, Providence College for Women, Coonoor - 643 104, India. \\ c. Department of Science and Humanities, Sathyabama University, Chennai - 600 119, India.
}

Received 23 April 2015; received in revised form 14 September 2015; accepted 16 January 2016

\author{
KEYWORDS \\ Nanofluid; \\ Entropy generation; \\ MHD; \\ Thermal radiation; \\ Non-uniform heat \\ source/sink; \\ Stretching sheet; \\ Partial slip.
}

\begin{abstract}
The application of second law of thermodynamics to an electrically conducting incompressible nanofluid slip flow over a stretching sheet is investigated in the presence of thermal radiation and non-uniform heat source/sink, both analytically and numerically. The governing dimensionless equations for this investigation are solved analytically by hypergeometric function and numerically by using Runge-Kutta-Gill method with shooting technique. The effects of magnetic parameter, nanosolid volume fraction parameter, slip parameter, and suction parameter on velocity profile are discussed for Ag nanoparticles. Further, in addition to these parameters, the effects of radiation parameter and non-uniform heat source/sink parameters on temperature profile and entropy generation number are also discussed. Finally, the results of these profiles of Ag nanoparticles are compared with those of the $\mathrm{Cu}, \mathrm{Al}_{2} \mathrm{O}_{3}$, and $\mathrm{TiO}_{2}$ nanoparticles. It is inferred that the effect of slip and non-uniform heat source parameters decrease the entropy generation. The metallic nanoparticles create more entropy than the non-metallic nanoparticles.
\end{abstract}

(C) 2016 Sharif University of Technology. All rights reserved.

\section{Introduction}

Nanofluid is a suspension of nanoparticles in a classical base fluid. Thermal conductivity of the base fluid can be substantially enhanced by addition of nanosize particles. Choi and Eastman [1] utilized a combination of nanoparticles and base fluid which resulted in nanofluids. Experimental studies have displayed that with $1-5 \%$ volume of solid metallic or metallic oxide particles, the effective thermal conductivity of the resulting mixture can increase by $20 \%$ compared to that of the base fluid [2-4]. The broad range of current and future applications involving nanofluids has

*. Corresponding author. Tel.: +919442401998 E-mail address: abdulhakeem6@gmail.com (A.K. Abdul Hakeem) motivated the researchers to find effective techniques for enhancing the heat transfer [5-8].

Magnetohydrodynamics is the science which deals with the motion of a highly conducting fluid in the presence of a magnetic field. The advantage of the hydromagnetic nanofluid is that fluid flow and heat transfer can be controlled by external magnetic field, which makes it applicable in various fields, viz. aerospace, electronic packing, and thermal engineering [9-11]. Hamad studied the natural convection flow of a nanofluid over a linearly stretching sheet with the effect of magnetic field [12]. Several studies have been reported in recent years on the effect of the magnetic field on water based nanofluid over a stretching surface $[13,14]$. The above mentioned studies have investigated the nanofluid properties with no-slip condition over stretching sheet. When the fluid is 
particulate, such as emulsions, suspensions, foams, and polymer solutions, the no-slip condition is inadequate. In such cases, the suitable boundary condition is the partial slip $[15,16]$. Abdul Hakeem et al. [17] investigated the partial slip effect on the flow of a Newtonian fluid over a stretching sheet. Recently, the slip effect on the Newtonian-type nanofluid flow over a stretching sheet has been considered by Das [18] and Turkyilmazoglu [19]. Noghrehabad and Pourrajab [20] and Ibrahim and Shankar [21] analyzed the slip effect on the non-Newtonian nanofluid model over a stretching sheet. Very recently, Abdul Hakeem et al. [22] investigated the second-order slip effects on MHD nanofluid flow over a stretching sheet in the presence of thermal radiation.

The second law of thermodynamics says that all the flow and heat transfer processes undergo irreversible changes. These changes are mostly caused by the energy losses during the processes. Although measures can be taken to reduce these irreversible effects, it is impossible to recover all the lost energy, which results in the increase of entropy. Due to this, the entropy generation rate is used as a standard metric to study the irreversibility effects. Aiboud and Saouli [23] demonstrated the application of the second law analysis of thermodynamics to viscoelastic MHD flow over a stretching surface. Since, extensive research has been made by scientists on the entropy generation in the flow and heat transfer systems [24-30]. The entropy generation, flow, and thermal boundary layer over an isothermal stretching sheet are theoretically analyzed in the presence of the slip boundary condition and internal heat generation/absorption [31]. The effect of hydrodynamic slip on entropy generation in a viscous flow over a vertical plate with convective boundary condition was observed by numerical technique, and shooting method [32]. Govindaraju et al. [33] investigated the entropy generation on the natural convection flow of nanofluid over a stretching sheet in the presence of magnetic field.

Another important aspect is that heat transfer processes play a vital role in all such theoretical studies. This is due to the fact that the rate of cooling significantly influences the quality of the final product with the desired characteristics. Abel and Nandeppanavar [34] studied the MHD viscoelastic flow over a stretching sheet with non-uniform heat source/sink.

Thermal radiation effects may play a pivotal role in controlling heat transfer in polymer processing industry, where the quality of the final product depends on the heat controlling factors. High temperature plasmas, nuclear reactors cooling, liquid metal fluids, hydromagnetic accelerators, and power generation systems are some important applications of radiative heat transfer from a vertical wall to conductive gray fluids. Abdul et al. $[35,36]$ reported the two-dimensional oscillatory flow on free convective-radiation of an incompressible viscous fluid through a highly porous medium bounded by an infinite vertical plate. Also, they analyzed the radiation effects on Walter's liquid B fluid flow over a stretching sheet.

The main scope of the present work is to analyze entropy generation of the hydromagnetic flow of an incompressible viscous nanofluid over a stretching sheet with partial slip, thermal radiation, and nonuniform heat source/sink effects, both analytically and numerically. The governing dimensionless equations for this investigation are solved analytically using hypergeometric function and numerically by Runge-KuttaGill method with shooting technique. The entropy generation is calculated using the entropy relation by substituting the velocity and temperature fields obtained from the momentum and energy equations.

\section{Formulation of the problem}

Consider a steady laminar two-dimensional radiative slip flow of an incompressible viscous nanofluid over a stretching sheet in the presence of magnetic field. The velocity of the stretching sheet is $\overline{u_{w}}=a \bar{x}$. We also consider influence of a constant magnetic field of strength $B_{0}$, which is applied normally to the sheet (see Figure 1). The temperature at the stretching surface takes the constant value $T_{w}$, while the ambient value, attained as $\bar{y}$, tends to infinity and takes the constant value $T_{\infty}$. It is further assumed that the induced magnetic field is negligible in comparison to the applied magnetic field (as the magnetic Reynolds number is small). The fluid is a water based nanofluid containing different types of nanoparticles: copper $(\mathrm{Cu})$, alumina $\left(\mathrm{Al}_{2} \mathrm{O}_{3}\right)$, silver $(\mathrm{Ag})$, and titanium oxide $\left(\mathrm{TiO}_{2}\right)$. It is assumed that the base fluid water and the nanoparticles are in thermal equilibrium and no slip occurs between them. The thermo-physical properties of the nanofluid are considered as in Table 1. Under the above assumptions, the boundary layer equations governing the flow and thermal fields can be written in

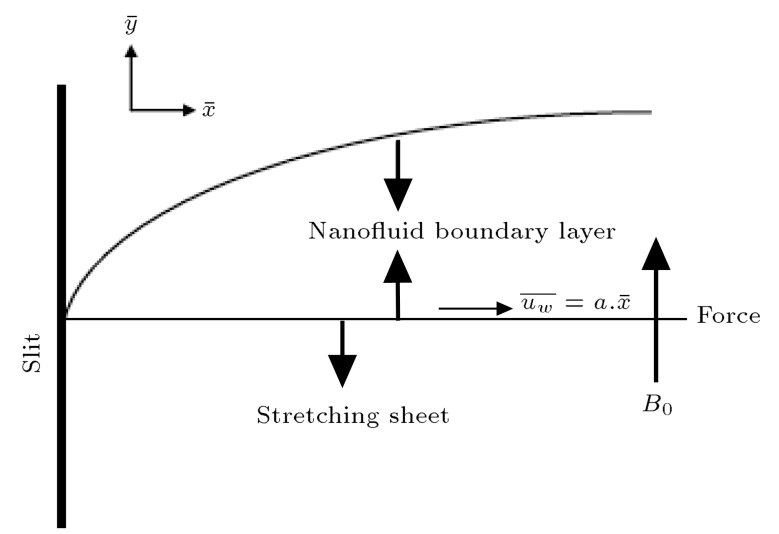

Figure 1. A sketch of the physical model. 
Table 1. Thermo-physical properties of water and nanoparticles [12].

\begin{tabular}{lcccc}
\hline & $\boldsymbol{\rho}\left(\mathbf{k g} / \mathbf{m}^{\mathbf{3}}\right)$ & $\boldsymbol{C}_{\boldsymbol{p}}(\mathbf{J} / \mathbf{k g k})$ & $\boldsymbol{k}(\mathbf{w} / \mathbf{m k})$ & $\boldsymbol{\beta} \times \mathbf{1 0}^{\mathbf{5}}\left(\mathbf{k}^{-\mathbf{1}}\right)$ \\
\hline Pure water & 997.1 & 4179 & 0.613 & 21 \\
Copper $(\mathrm{Cu})$ & 8933 & 385 & 401 & 1.67 \\
Silver $(\mathrm{Ag})$ & 10500 & 235 & 429 & 1.89 \\
Alumina $\left(\mathrm{Al}_{2} \mathrm{O}_{3}\right)$ & 3970 & 765 & 40 & 0.85 \\
Titanium oxide $\left(\mathrm{TiO}_{2}\right)$ & 4250 & 686.2 & 8.9538 & 0.9 \\
\hline
\end{tabular}

dimensional form as $[11,12,22]$ :

$$
\begin{aligned}
& \frac{\partial \bar{u}}{\partial \bar{x}}+\frac{\partial \bar{v}}{\partial \bar{y}}=0, \\
& \rho_{n f}\left(\bar{u} \frac{\partial \bar{u}}{\partial \bar{x}}+\bar{v} \frac{\partial \bar{u}}{\partial \bar{y}}\right)=\mu_{n f} \frac{\partial^{2} \bar{u}}{\partial \bar{y}^{2}}-\sigma B_{0}^{2} \bar{u}, \\
& \left(\rho c_{p}\right)_{n f}\left(\bar{u} \frac{\partial T}{\partial \bar{x}}+\bar{v} \frac{\partial T}{\partial \bar{y}}\right)=k_{n f} \frac{\partial^{2} T}{\partial \bar{y}^{2}}-\frac{\partial q_{r}}{\partial \bar{y}}+q^{\prime \prime \prime} .
\end{aligned}
$$

Here, $\bar{x}$ and $\bar{y}$ are the coordinates along and perpendicular to the sheet; $\bar{u}$ and $\bar{v}$ are velocity components in the $\bar{x}$ and $\bar{y}$ directions, respectively; $T$ is the local temperature of the fluid; $\sigma$ is the electric conductivity; $q_{r}$ is the radiative heat flux; and $q^{\prime \prime \prime}$ is the rate of nonuniform heat generation/absorption coefficient. The dimensionless form of $q^{\prime \prime \prime}$ can be defined as $[17,36]$ :

$q^{\prime \prime \prime}=\left(\frac{k_{n f} \bar{u}_{w}(\bar{x})}{\bar{x} \nu_{n f}}\right)\left[A^{*}\left(T_{w}-T_{\infty}\right) F^{\prime}(\eta)+B^{*}\left(T-T_{\infty}\right)\right]$,

where $A^{*}$ and $B^{*}$ are parameters of the space and temperature-dependent internal heat generation/absorption. The cases $A^{*}>0$ and $B^{*}>0$ correspond to internal heat generation, while $A^{*}<0$ and $B^{*}<0$ correspond to internal absorption. Using Rosseland approximation for radiation (see $[35,36]$ ), we have:

$$
q_{r}=-\frac{4 \sigma^{*}}{3 k_{n f}^{*}} \frac{\partial T^{4}}{\partial \bar{y}} .
$$

Here, $\sigma^{*}$ is the Stefan-Bolltzmann constant and $k_{n f}^{*}$ is the absorption coefficient of the nanofluid. Further, we assume that the temperature difference within the flow is such that $T^{4}$ may be expanded in a Taylor series. Hence, expanding $T^{4}$ about $T_{\infty}$ and neglecting higher order terms, we get:

$$
T^{4} \cong 4 T_{\infty}^{3} T-3 T_{\infty}^{4} .
$$

Therefore, Eq. (3) is simplified to:

$$
\begin{aligned}
\bar{u} \frac{\partial T}{\partial \bar{x}} & +\bar{v} \frac{\partial T}{\partial \bar{y}}=\frac{k_{n f}}{\left(\rho c_{p}\right)_{n f}} \frac{\partial^{2} T}{\partial \bar{y}^{2}}+\frac{16 \sigma^{*} T_{\infty}^{3}}{3\left(\rho c_{p}\right)_{n f} k_{n f}^{*}} \frac{\partial^{2} T}{\partial \bar{y}^{2}} \\
& +\left(\frac{k_{n f} \bar{u}_{w}(\bar{x})}{\bar{x}\left(\rho c_{p}\right)_{n f} \nu_{n f}}\right)\left[A^{*}\left(T_{w}-T_{\infty}\right) F^{\prime}(\eta)\right. \\
& \left.+B^{*}\left(T-T_{\infty}\right)\right] .
\end{aligned}
$$

The effective density of the nanofluid, $\rho_{n f}$, the effective dynamic viscosity of the nanofluid, $\mu_{n f}$, the heat capacitance of the nanofluid, $\left(\rho C_{p}\right)_{n f}$, and the thermal conductivity, $k_{n f}$, of the nanofluid are given as:

$$
\begin{aligned}
& \rho_{n f}=(1-\phi) \rho_{f}+\phi \rho_{s}, \\
& \mu_{n f}=\frac{\mu_{f}}{(1-\phi)^{2.5}} \\
& \left(\rho C_{p}\right)_{n f}=(1-\phi)\left(\rho C_{p}\right)_{f}+\phi\left(\rho C_{p}\right)_{s}, \\
& k_{n f}=k_{f}\left(\frac{k_{s}+2 k_{f}-2 \phi\left(k_{f}-k_{s}\right)}{k_{s}+2 k_{f}+\phi\left(k_{f}-k_{s}\right)}\right) .
\end{aligned}
$$

Here, $\phi$ is the solid volume fraction.

The boundary conditions of Eqs. (1)-(3) are:

$$
\begin{aligned}
& \bar{u}=a \bar{x}+l \frac{\partial \bar{u}}{\partial \bar{y}}, \quad \bar{v}=0, \quad T=T_{w} \quad \text { at } \quad y=0 \\
& \bar{u} \rightarrow 0, \quad T \rightarrow T_{\infty}, \quad \text { as } \quad y \rightarrow \infty
\end{aligned}
$$

where $\mu_{f}$ is the dynamic viscosity of the basic fluid, $\rho_{f}$ and $\rho_{s}$ are the densities of the base fluid and nanoparticles, respectively, $\left(\rho C_{p}\right)_{f}$ and $\left(\rho C_{p}\right)_{s}$ are the specific heat parameters of the base fluid and nanoparticles, respectively, $k_{f}$ and $k_{s}$ are the thermal conductivities of the base fluid and nanoparticles, respectively, and $a$ is constant.

By introducing the following non-dimensional variables:

$$
\begin{array}{ll}
x=\frac{\bar{x}}{\sqrt{\nu_{f} / a}}, & y=\frac{\bar{y}}{\sqrt{\nu_{f} / a}}, \\
u=\frac{\bar{u}}{\sqrt{a \nu_{f}}}, & v=\frac{\bar{v}}{\sqrt{a \nu_{f}}}, \\
\theta=\frac{T-T_{\infty}}{T_{w}-T_{\infty}}, &
\end{array}
$$

Eqs. (1) to (3) take the following non-dimensional form:

$$
\begin{aligned}
& \frac{\partial u}{\partial x}+\frac{\partial v}{\partial y}=0 \\
& u \frac{\partial u}{\partial x}+v \frac{\partial u}{\partial y}=\frac{1}{\left(1-\phi+\phi \rho_{s} / \rho_{f}\right)} \frac{1}{(1-\phi)^{2.5}} \frac{\partial^{2} u}{\partial y^{2}} \\
& -M_{n} u
\end{aligned}
$$




$$
\begin{aligned}
u \frac{\partial \theta}{\partial x} & +v \frac{\partial \theta}{\partial y}=\left(\frac{3 \mathrm{Nr}+4}{3 \mathrm{Nr}}\right) \frac{1}{\operatorname{Pr}} \\
& \frac{1}{\left(1-\phi+\phi\left(\rho C_{p}\right)_{s} /\left(\rho C_{p}\right)_{f}\right)}\left(\frac{k_{n f}}{k_{f}}\right) \frac{\partial^{2} \theta}{\partial y^{2}} \\
& +\frac{k_{n f}}{k_{f} \operatorname{Pr}} \frac{(1-\phi)^{2.5}\left(1-\phi+\phi \rho_{s} / \rho_{f}\right)}{\left(1-\phi+\phi\left(\rho C_{p}\right)_{s} /\left(\rho C_{p}\right)_{f}\right)} \\
& {\left[A^{*} F^{\prime}(\eta)+B^{*} \theta(\eta)\right] }
\end{aligned}
$$

with the boundary conditions:

$$
\begin{aligned}
& u=x+L \frac{\partial \bar{u}}{\partial \bar{y}}, \quad v=0, \quad \theta=1 \quad \text { at } y=0, \\
& u \rightarrow 0, \quad \theta \rightarrow 0, \quad \text { as } \quad y \rightarrow \infty
\end{aligned}
$$

where $\operatorname{Pr}=\frac{\nu_{f}}{\alpha_{f}}$ is the Prandtl number, $M_{n}=\frac{\sigma B_{0}^{2}}{a \rho_{f}}$ is the magnetic parameter, and $\mathrm{Nr}=\frac{k_{n f} k_{n f}^{*}}{4 \sigma T_{\infty}^{3}}$ is the Radiation parameter.

By introducing the stream function $\psi$, which is defined as $u=\partial \psi / \partial y$ and $v=-\partial \psi / \partial x$, Systems (12) and (13) become:

$$
\begin{gathered}
\frac{\partial \psi}{\partial y} \frac{\partial^{2} \psi}{\partial x \partial y}-\frac{\partial \psi}{\partial x} \frac{\partial^{2} \psi}{\partial y^{2}} \\
=\frac{1}{\left(1-\phi+\phi \rho_{s} / \rho_{f}\right)}\left\{\frac{1}{(1-\phi)^{2.5}} \frac{\partial^{2} \psi}{\partial y^{2}}\right. \\
\left.-M_{n} \frac{\partial \psi}{\partial y}\right\}, \\
\frac{\partial \psi}{\partial y} \frac{\partial \theta}{\partial x}-\frac{\partial \psi}{\partial x} \frac{\partial \theta}{\partial y}=\left(\frac{3 \mathrm{Nr}+4}{3 \mathrm{Nr}}\right) \frac{1}{\operatorname{Pr}} \\
\frac{1}{\left(1-\phi+\phi\left(\rho C_{p}\right)_{s} /\left(\rho C_{p}\right)_{f}\right)}\left(\frac{k_{n f}}{k_{f}}\right) \frac{\partial^{2} \theta}{\partial y^{2}} \\
+\frac{k_{n f}}{k_{f} \operatorname{Pr}} \frac{(1-\phi)^{2.5}\left(1-\phi+\phi \rho_{s} / \rho_{f}\right)}{\left(1-\phi+\phi\left(\rho C_{p}\right)_{s} /\left(\rho C_{p}\right)_{f}\right)} \\
{\left[A^{*} F^{\prime}(\eta)+B^{*} \theta(\eta)\right],}
\end{gathered}
$$

with the boundary conditions:

$$
\begin{aligned}
& \frac{\partial \psi}{\partial y}=x+L \frac{\partial^{2} \psi}{\partial y^{2}}, \quad \frac{\partial \psi}{\partial x}=0, \quad \theta=1 \quad \text { at } \quad y=0 \\
& \frac{\partial \psi}{\partial y} \rightarrow 0, \quad \theta \rightarrow 0, \quad \text { as } \quad y \rightarrow \infty
\end{aligned}
$$

Now, by using the simplified form of Lie-group transformations, viz. the scaling group $\mathrm{G}$ of transformations (see [12]), we get the similarity transformations as:

$$
\eta=y, \quad \psi=x F(\eta), \quad \theta=\theta(\eta) .
$$

\section{Solution of flow field}

Now, using the similarity transformations in Eqs. (15) and (16), we get:

$$
\begin{aligned}
F_{\eta \eta \eta}+ & (1-\phi)^{2.5}\left\{[ 1 - \phi + \phi ( \rho _ { s } / \rho _ { f } ) ] \left(F F_{\eta \eta}\right.\right. \\
& \left.\left.-F_{\eta}^{2}\right)-M_{n} F_{\eta}\right\}=0 \\
\theta_{\eta \eta}+ & \left(\frac{3 \mathrm{Nr}}{3 \mathrm{Nr}+4}\right) \frac{\operatorname{Pr} k_{f}\left[1-\phi+\phi\left(\rho C_{p}\right)_{s} /\left(\rho C_{p}\right)_{f}\right]}{k_{n f}} \\
& \left\{S+X\left(\frac{1-e^{-m \eta}}{m}\right)\right\} \theta_{\eta}+(1-\phi)^{2.5} \\
& \left(1-\phi+\phi \rho_{s} / \rho_{f}\right)\left(\frac{3 \mathrm{Nr}}{3 \mathrm{Nr}+4}\right) B^{*} \theta=-(1-\phi)^{2.5} \\
& \left(1-\phi+\phi \rho_{s} / \rho_{f}\right)\left(\frac{3 \mathrm{Nr}}{3 \mathrm{Nr}+4}\right) A^{*} X e^{-m \eta}, \quad(20)
\end{aligned}
$$

with the boundary conditions becoming:

$F(0)=S, \quad F^{\prime}(0)=1+L F^{\prime \prime}(0), \quad \theta(0)=1$ at $\eta=0$,

$$
F^{\prime}(\infty)=0, \quad \theta(\infty)=0 \quad \text { as } \quad \eta \rightarrow \infty .
$$

The exact solution to the differential equation (Eq. (16)) satisfying the boundary condition (17) is obtained as (see [17]):

$$
F(\eta)=S+X\left(\frac{1-e^{-m \eta}}{m}\right)
$$

where $m$ is the parameter associated with the nanoparticle volume fraction, the magnetic field parameter, the fluid density, and the nanoparticle density as follows:

$$
m=\frac{-0.3333 \frac{\alpha_{1}}{L}-\left(0.4199\left(3 \alpha_{2}-\alpha_{1}^{2}\right)\right)}{L\left(\alpha_{3}+\sqrt{\alpha_{3}^{2}+4 \alpha_{4}^{3}}\right)^{1 / 3}+\frac{0.2645 \alpha_{3}+\sqrt{\left(\alpha_{3}^{2}+4 \alpha_{4}^{4}\right)^{1 / 3}}}{L}},
$$

where:

$$
\begin{aligned}
& \alpha_{1}= \\
& \frac{\rho_{f}-L S(1-\phi)^{2.5} \rho_{f}+L S(1-\phi)^{2.5} \phi \rho_{f}-L S(1-\phi)^{2.5} \phi \rho_{s}}{\rho_{f}} \\
& \alpha_{2}=\frac{L(1-\phi)^{2.5}\left(-L M \rho_{f}-S \rho_{f}+S \phi \rho_{f}-S \phi \rho_{s}\right)}{\rho_{f}} \\
& \alpha_{3}=-2+27 L A_{2}+18 L A_{2}-3 S A_{2}+9 M S L A_{2}^{2} \\
&+3 S^{2} A_{2}^{2}+2 A_{2}^{3} S^{3}-27 L A_{2} \phi+3 S A_{2} \phi \\
&-9 L M S A_{2}^{2} \phi-6 A_{2}^{2} S^{2} \phi-6 A_{2}^{3} S^{3} \phi \\
&+3 A_{2}^{2} S^{2} \phi^{2}+6 A_{2}^{3} S^{3} \phi^{2}-2 A_{2}^{3} S^{3} \phi^{3} \\
&+9 L A_{1}-S A_{1}+3 L A_{1}^{2} M S+2 A_{2} L A_{1}^{2} S^{2}
\end{aligned}
$$




$$
\begin{aligned}
& +2 A_{1}^{3} S^{3}-3 A_{1}^{2} S^{2}-4 A_{1}^{3} S^{3}+2 A_{1}^{3} S^{3} \\
& +A_{1}^{2} S^{2}+2 A_{1}^{3} S^{3}-2 A_{1}^{3}+0.667 A_{1}^{3} S^{3} \\
\alpha_{4}= & \frac{3 A_{2}\left(-L M \rho_{f}-S \rho_{f}-S \rho_{f}+S \phi \rho_{s}\right)}{\rho_{f}} \\
& -\frac{\left(\rho_{f}-S A_{2} \rho_{f}+A_{2} S \phi \rho_{f}-S A_{2} \phi \rho_{s}\right)^{2}}{\rho_{f}^{2}}, \\
A_{1}= & \frac{3 L(1-\phi)^{2.5} \phi \rho_{s}}{\rho_{f}}, \\
A_{2}= & L(1-\phi)^{2.5} \quad \text { and } \quad X=\frac{1}{L m+1} .
\end{aligned}
$$

Thus, the non-dimensional velocity components are:

$$
u=x X e^{-m \eta}, \quad v=-\left(S+X\left(\frac{1-e^{-m \eta}}{m}\right)\right)_{(2)}
$$

The dimensional velocity components are:

$$
\begin{aligned}
& \bar{u}=X a \bar{x} e^{-m \sqrt{a / \nu_{f}} \bar{y}}, \\
& \bar{v}=-\left(S+X\left(\frac{1-e^{-m \sqrt{a / \nu_{f}} \bar{y}}}{m}\right)\right) \sqrt{a v_{f}} .
\end{aligned}
$$

The shear stress at the stretching sheet characterized by the skin friction coefficient, $C_{f}$, is given by:

$$
C_{f}=\frac{-2 \mu_{n f}}{\rho_{f}\left(\bar{u}_{w}(\bar{x})\right)^{2}}\left(\frac{\partial \bar{u}}{\partial \bar{y}}\right)_{\bar{y}=0} .
$$

Using Eqs. (10), (18), (22), (23) and (25), the skin friction can be written as:

$$
\operatorname{Re}_{x}^{1 / 2} C_{f}=-\frac{2}{(1-\phi)^{2.5}} F^{\prime \prime}(0)
$$

where $\operatorname{Re}_{x}=\bar{x} \bar{u}_{w}(\bar{x}) / \nu_{f}$ is the local Reynolds number based on the stretching velocity $\bar{u}_{w}(\bar{x}) \cdot \operatorname{Re}_{x}^{1 / 2} C_{f}$ is the local skin friction coefficient.

\section{Analytical method for solution}

Introducing the new variable:

$$
\xi=-\frac{\operatorname{Pr} k_{f}\left[1-\phi+\phi\left(\rho C_{p}\right)_{s} /\left(\rho C_{p}\right)_{f}\right]}{m^{2} k_{n f}}\left(\frac{3 \mathrm{Nr}}{3 \mathrm{Nr}+4}\right) X e^{-m \eta},
$$

and inserting Eq. (28) in Eq. (20), we obtain:

$$
\begin{aligned}
\xi \theta_{\xi \xi} & +\left(1-a_{0}-\xi\right) \theta_{\xi}+\left(\frac{3 \mathrm{Nr}}{3 \mathrm{Nr}+4}\right) \frac{\beta B^{*}}{m^{2} \xi} \theta \\
& =-A^{*} \frac{\beta}{m^{2} \xi}\left(\frac{3 \mathrm{Nr}}{3 \mathrm{Nr}+4}\right) X e^{-m \eta}
\end{aligned}
$$

and Eq. (20) is transformed into:

$$
\theta\left(-\frac{\operatorname{Pr}}{\alpha m^{2}}\right)=1, \quad \theta(0)=0,
$$

where:

$$
\begin{aligned}
& \alpha=\frac{k_{n f}}{k_{f}\left(1-\phi+\phi \frac{\left(\rho C_{p}\right)_{s}}{\left(\rho C_{p}\right)_{f}}\right)} \\
& a_{0}=\frac{\operatorname{Pr}}{\alpha}\left(\frac{3 \mathrm{Nr}}{3 \mathrm{Nr}+4}\right)\left(\frac{S}{m}+\frac{X}{m^{2}}\right), \\
& b_{0}=\sqrt{a^{2}-0-4 \frac{\beta B^{*}}{m^{2}}\left(\frac{3 N r}{3 N r+4}\right),} \\
& \beta=(1-\phi)^{2.5}\left(1-\phi+\frac{\rho_{s}}{\rho_{f}}\right) .
\end{aligned}
$$

The solution of Eq. (29) in terms of $\eta$ with $A^{*}=0$ is written as:

$$
\begin{aligned}
\theta(\eta)= & e^{-m \frac{a_{0}+b_{0}}{2} \eta} c_{1} M\left[\frac{a_{0}+b_{0}}{2}, b_{0}+1\right. \\
& \left.-\frac{\operatorname{Pr}}{\alpha m^{2}}\left(\frac{3 \mathrm{Nr}}{3 \mathrm{Nr}+4}\right) X e^{-m \eta}\right]+c_{2} e^{-2 m \eta},
\end{aligned}
$$

where:

$$
M\left[\frac{a_{0}+b_{0}}{2}, b_{0}+1,-\frac{\operatorname{Pr}}{\alpha m^{2}}\left(\frac{3 \mathrm{Nr}}{3 \mathrm{Nr}+4}\right) X e^{-m \eta}\right],
$$

is the Kummer's function (see [37]):

$$
c_{1}=\frac{1-c_{2}}{M\left[\frac{a_{0}+b_{0}}{2}, b_{0}+1,-\frac{\operatorname{Pr}}{\alpha m^{2}}\left(\frac{3 \mathrm{Nr}}{3 \mathrm{Nr}+4}\right) X\right]},
$$

and:

$c_{2}=$

$$
-\frac{\beta \operatorname{Pr}\left(\frac{3 \mathrm{Nr}}{3 \mathrm{Nr}+4}\right)^{2} A^{*} X^{2}}{\alpha m^{4}\left(1-a_{0}+\left(\frac{3 \mathrm{Nr}}{3 \mathrm{Nr}+4}\right) \frac{\beta B^{*}}{m^{2}}\right)\left(4-2 a_{0}+\left(\frac{3 \mathrm{Nr}}{3 \mathrm{Nr}+4}\right) \frac{\beta B^{*}}{m^{2}}\right)} .
$$

The Nusselt number, $N u_{x}$, is defined as:

$$
\mathrm{Nu}_{x}=\frac{\overline{x q}_{w}}{k_{f}\left(T_{w}-T_{\infty}\right)},
$$

where:

$$
\bar{q}_{w}=-\left(k_{n f}+\frac{16 \sigma T_{\infty}^{3}}{3 k_{n f}^{*}}\right)\left(\frac{\partial T}{\partial \bar{y}}\right)_{\bar{y}=0},
$$

is the local surface heat flux.

We obtain the following Nusselt number: 


$$
\operatorname{Re}_{x}^{-1 / 2} \mathrm{Nu}_{x}=\frac{k_{n f}}{k_{f}}\left(\frac{3 \mathrm{Nr}+4}{3 \mathrm{Nr}}\right)\left[-\theta^{\prime}(0)\right]
$$

where:

$$
\begin{aligned}
\theta^{\prime}(0)= & c_{1}\left\{( - m \frac { a _ { 0 } + b _ { 0 } } { 2 } ) M \left[\frac{a_{0}+b_{0}}{2}, b_{0}+1,\right.\right. \\
& \left.\left.-\frac{\operatorname{Pr}}{\alpha m^{2}}\left(\frac{3 \mathrm{Nr}}{3 \mathrm{Nr}+4}\right) X\right]\right\} \\
& +c_{1}\left\{\frac{a_{0}+b_{0}}{2\left(1+b_{0}\right)} \frac{\operatorname{Pr}}{\alpha m}\left(\frac{3 \mathrm{Nr}}{3 \mathrm{Nr}+4}\right) X M\right. \\
& {\left.\left[\frac{a_{0}+b_{0}+2}{2}, b_{0}+2,-\frac{\operatorname{Pr}}{\alpha m^{2}}\left(\frac{3 \mathrm{Nr}}{3 \mathrm{Nr}+4}\right) X\right]\right\} } \\
& -2 m c_{2} .
\end{aligned}
$$

\section{Numerical method for solution}

The set of non-linear ordinary differential equations (19), (20) with boundary conditions (21) have been solved using Runge-Kutta-Gill method with shooting technique with an orderly guessing of $F_{\eta \eta}(0)$ and $\theta_{\eta}(0)$. The procedure is repeated until we get the results up to the desired degree of accuracy, vis. $10^{-8}$ with $M_{n}, \phi, S, L, A^{*}, B^{*}$ and $\mathrm{Nr}$ as prescribed parameters. A code is $\mathrm{C}++$ package and the numerical solutions are presented in tabular form.

\section{Entropy generation analysis}

The local volumetric rate of entropy generation in the presence of a magnetic field and thermal radiation for nanofluids can be expressed [38-40] as:

$$
\begin{aligned}
S_{G}= & \frac{k_{n f}}{T_{\infty}^{2}}\left[\left(\frac{\partial T}{\partial \bar{x}}\right)^{2}+\left(1+\frac{16 \sigma^{*} T_{\infty}^{3}}{3 k_{n f}^{*} k_{n f}}\right)\left(\frac{\partial T}{\partial \bar{y}}\right)^{2}\right] \\
& +\frac{\mu_{n f}}{T_{\infty}}\left(\frac{\partial \bar{u}}{\partial \bar{y}}\right)^{2}+\frac{\sigma B_{0}^{2}}{T_{\infty}} \bar{u}^{2} .
\end{aligned}
$$

The contributions of three sources of entropy generation are considered in Eq. (33). The first term indicates the entropy generation due to heat transfer across a finite temperature difference, the second term the local entropy generation due to viscous dissipation, and the third term the local entropy generation due to the effect of the magnetic field. A dimensionless number for entropy generation rates, $N_{S}$, is defined as the ratio of the local volumetric entropy generation rate $\left(S_{G}\right)$ to a characteristic entropy generation rate $\left(S_{G}\right)_{0}$. For a prescribed boundary condition, the characteristic entropy generation rate is:

$$
\left(S_{G}\right)_{0}=\frac{k_{n f}(\Delta T)^{2}}{\bar{x}^{2} T_{\infty}^{2}}
$$

therefore, the entropy generation number is:

$$
N_{s}=\frac{S_{G}}{\left(S_{G}\right)_{0}} .
$$

Using Eqs. (31), (33), and (34), the entropy generation number is given by:

$$
\begin{aligned}
N_{s}= & \left(\frac{3 N_{r}+4}{3 N_{r}}\right) \theta^{\prime 2}(\eta) \operatorname{Re}_{x}+\frac{\mathrm{Br}}{\Omega} F^{\prime \prime 2}(\eta) \operatorname{Re}_{x} \\
& +\frac{\mathrm{BrHa}^{2}}{\Omega} F^{\prime 2}(\eta),
\end{aligned}
$$

where $\mathrm{Br}$ is the Brinkman number; and $\Omega$ and $\mathrm{Ha}$ are, respectively, the dimensionless temperature difference and the Hartman number. These numbers are given by the following relationships:

$$
\mathrm{Br}=\frac{\mu_{n f} \bar{u}_{w}^{2}}{k_{n f} \Delta T}, \quad \Omega=\frac{\Delta T}{T_{\infty}}, \quad \mathrm{Ha}=B_{0} \bar{x} \sqrt{\frac{\sigma}{\mu_{n f}}} .
$$

\section{Results and discussion}

In order to gain a clear insight into the physical problem, the results are discussed with the help of graphical illustrations for $\mathrm{Ag}$-water. The effects of magnetic parameter, nanosolid volume fraction parameter, slip parameter, and suction parameter on velocity profile are discussed for Ag nanoparticles. Further, in addition to these parameters, the effects of radiation parameter and non-uniform heat source/sink parameters on temperature profile and entropy generation number are also discussed. The Prandtl number is fixed on 6.2 for base fluid water. For verification of the accuracy of the applied numerical scheme, a comparison of the results corresponding to the values of $-\theta^{\prime}(0)$ (i.e., in the absence of $S, M_{n}, N_{r}, A^{*}, \phi, L$, and $B^{*}$ ) with the available published results of Wang [41] is made and presented in Table 2. The results are found in excellent agreement. The values of local skin

Table 2. Comparison of results for the reduced Nusselt number $-\theta^{\prime}(0)$. When $\phi=M_{n}=\mathrm{Nr}=L=S=A^{*}=$ $B^{*}=0$

\begin{tabular}{cccc}
\hline \multirow{2}{*}{ Pr } & \multicolumn{2}{c}{ Present results } & \multirow{2}{*}{ Wang [41] } \\
\cline { 2 - 3 } & Analytical & Numerical & \\
\hline 0.7 & 0.453916 & 0.453916 & 0.4539 \\
2 & 0.911358 & 0.911358 & 0.9114 \\
7 & 1.895400 & 1.895403 & 1.8954 \\
20 & 3.353900 & 3.353904 & 3.3539 \\
\hline
\end{tabular}


Table 3. Values of $-F^{\prime \prime}(0)$ for various parameters.

\begin{tabular}{|c|c|c|c|c|c|c|c|c|c|}
\hline \multirow{2}{*}{ Parameters } & \multirow{2}{*}{ Values } & \multicolumn{2}{|c|}{$\mathrm{Cu}$} & \multicolumn{2}{|c|}{$\mathrm{Ag}$} & \multicolumn{2}{|c|}{$\mathrm{Al}_{2} \mathrm{O}_{3}$} & \multicolumn{2}{|c|}{$\mathrm{TiO}_{2}$} \\
\hline & & Analytical & Numerical & Analytical & Numerical & Analytical & Numerical & Analytical & Numerical \\
\hline \multirow{3}{*}{ Mn } & 0.0 & 0.547029 & 0.54702851 & 0.559587 & 0.55958739 & 0.499649 & 0.49964899 & 0.502710 & 0.50270989 \\
\hline & 0.5 & 0.580735 & 0.58073532 & 0.590605 & 0.59060545 & 0.545079 & 0.54507934 & 0.547301 & 0.54730165 \\
\hline & 1.0 & 0.606464 & 0.60646417 & 0.614623 & 0.61462290 & 0.577746 & 0.57774636 & 0.579500 & 0.57949966 \\
\hline & 0.0 & 0.593809 & 0.59380894 & 0.593809 & 0.59380894 & 0.593809 & 0.59380894 & 0.593809 & 0.59380894 \\
\hline & 0.05 & 0.602680 & 0.60268038 & 0.607441 & 0.60744081 & 0.586680 & 0.58668038 & 0.587623 & 0.58762331 \\
\hline & 0.1 & 0.606464 & 0.60646417 & 0.614623 & 0.61462290 & 0.577746 & 0.57774636 & 0.579500 & 0.57949966 \\
\hline & 0.6 & 0.817901 & 0.81790118 & 0.832594 & 0.83259404 & 0.766614 & 0.76661372 & 0.769727 & 0.76972651 \\
\hline & 0.8 & 0.695817 & 0.69581661 & 0.706502 & 0.70650234 & 0.658322 & 0.65832156 & 0.660606 & 0.66060576 \\
\hline & 1.0 & 0.606464 & 0.60646417 & 0.614623 & 0.61462290 & 0.577746 & 0.57774636 & 0.579500 & 0.57949966 \\
\hline \multirow{3}{*}{. } & 0.2 & 0.567912 & 0.56791163 & 0.573774 & 0.57377352 & 0.547268 & 0.54726767 & 0.548529 & 0.54852912 \\
\hline & 0.4 & 0.593735 & 0.59373482 & 0.601159 & 0.60115900 & 0.567634 & 0.56763418 & 0.569227 & 0.56922673 \\
\hline & 0.6 & 0.618996 & 0.61899564 & 0.627843 & 0.62784312 & 0.587774 & 0.58777407 & 0.589683 & 0.58968303 \\
\hline
\end{tabular}

Note: While studying the effect of individual parameters the following values are assumed: $\operatorname{Pr}=6.2, M_{n}=1.0, \phi=0.1, L=1.0$ and $S=0.5$.

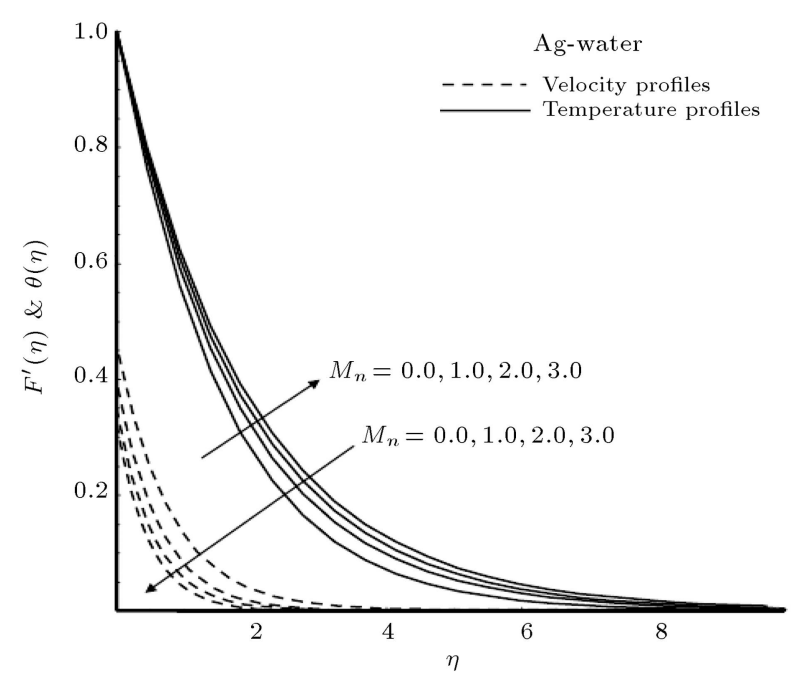

Figure 2. Effect of magnetic parameter on velocity and temperature distributions with $\operatorname{Pr}=6.2, \phi=0.1$, $\mathrm{Nr}=0.3, L=1.0, S=0.5, A^{*}=0.03$, and $B^{*}=0.03$.

friction coefficient and reduced Nusselt number are calculated and presented in Tables 3 and 4 for different nanoparticles like $\mathrm{Cu}, \mathrm{Ag}, \mathrm{Al}_{2} \mathrm{O}_{3}$, and $\mathrm{TiO}_{2}$.

Figure 2 exhibits the effect of magnetic parameter on velocity and temperature profiles. With increasing values of magnetic parameter, nanofluid velocity is found to decrease. Actually, rate of transport decreases with the increase in magnetic parameter, because the Lorentz force, which opposes the motion of fluid, increases with an increase in magnetic parameter. It is also evident that the increasing values of magnetic parameter cause the nanofluid to become warmer and therefore its temperature increases. It is obvious that

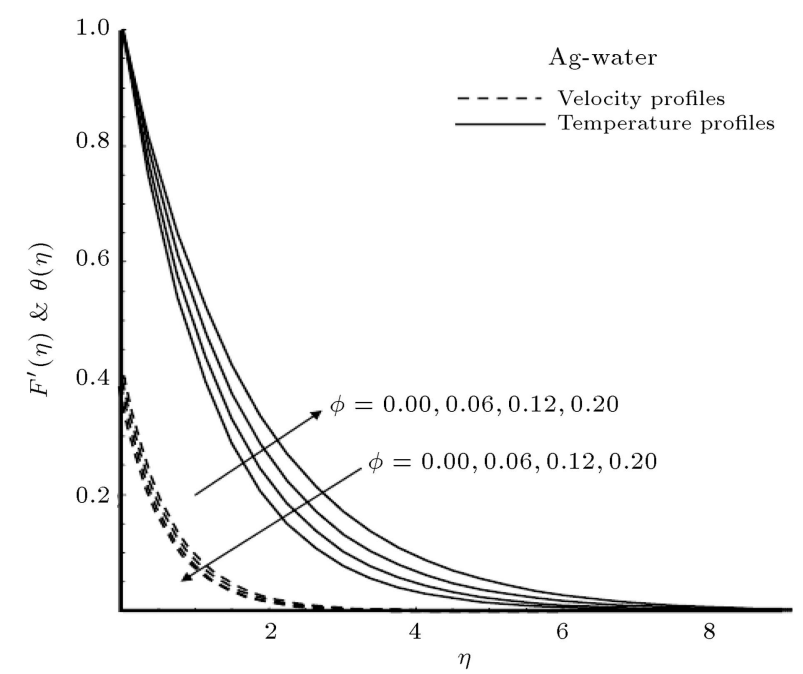

Figure 3. Effect of nanoparticles volume fraction parameter on velocity and temperature distributions with $\mathrm{Pr}=6.2, M_{n}=1.0, \mathrm{Nr}=0.3, L=1.0, S=0.5$, $A^{*}=0.03$, and $B^{*}=0.03$.

the presence of the magnetic field leads to thickening of the thermal boundary layer and, at the same time, thermal conductivity of nanoparticle is higher; therefore, there is an immediate heat distribution between the nanoparticles and the fluid.

The effect of nanosolid volume fraction on the velocity and temperature profiles is shown in Figure 3. It is noted that the increasing values of the nanosolid volume fraction parameter decrease the velocity profile. This is due to the fact that the presence of nanosolid-particles leads to the thinning of the boundary layer. The temperature of the nanofluid increases with 
Table 4. Values of $-\theta^{\prime}(0)$ for various parameters.

\begin{tabular}{|c|c|c|c|c|c|}
\hline Parameters & Values & $\mathrm{Cu}$ & $\mathrm{Ag}$ & $\mathrm{Al}_{2} \mathrm{O}_{3}$ & $\mathrm{TiO}_{2}$ \\
\hline \multirow{3}{*}{ Mn } & 0.0 & 0.610599 & 0.585283 & 0.655819 & 0.673524 \\
\hline & 0.5 & 0.582079 & 0.559548 & 0.616530 & 0.634507 \\
\hline & 1.0 & 0.561041 & 0.540347 & 0.588938 & 0.606958 \\
\hline \multirow{3}{*}{$\phi$} & 0.0 & 0.765017 & 0.765017 & 0.765017 & 0.765017 \\
\hline & 0.05 & 0.652466 & 0.640461 & 0.668816 & 0.679306 \\
\hline & 0.1 & 0.561041 & 0.540347 & 0.588938 & 0.606958 \\
\hline \multirow{3}{*}{$L$} & 0.6 & 0.597489 & 0.575425 & 0.628192 & 0.646953 \\
\hline & 0.8 & 0.577121 & 0.555794 & 0.606374 & 0.624715 \\
\hline & 1.0 & 0.561041 & 0.540347 & 0.588938 & 0.606958 \\
\hline \multirow{3}{*}{$S$} & 0.2 & 0.360262 & 0.343998 & 0.387503 & 0.398516 \\
\hline & 0.4 & 0.492257 & 0.473084 & 0.520069 & 0.535648 \\
\hline & 0.6 & 0.631462 & 0.609229 & 0.659302 & 0.679844 \\
\hline \multirow{3}{*}{$A^{*}$} & -0.3 & 0.581526 & 0.561537 & 0.606545 & 0.624731 \\
\hline & 0.0 & 0.562903 & 0.542274 & 0.590539 & 0.608573 \\
\hline & 0.3 & 0.544280 & 0.523011 & 0.574533 & 0.592416 \\
\hline \multirow{3}{*}{$B^{*}$} & -0.3 & 0.672031 & 0.664052 & 0.666812 & 0.684407 \\
\hline & 0.0 & 0.572760 & 0.553707 & 0.596764 & 0.614714 \\
\hline & 0.3 & 0.419995 & 0.358508 & 0.507451 & 0.526782 \\
\hline \multirow{3}{*}{$\mathrm{Nr}$} & 0.3 & 0.561041 & 0.540347 & 0.588938 & 0.606958 \\
\hline & 0.5 & 0.812908 & 0.785502 & 0.845710 & 0.871450 \\
\hline & 0.7 & 1.008384 & 0.976030 & 1.044053 & 1.075840 \\
\hline
\end{tabular}

Note: While studying the effect of individual parameters the following values are assumed: $\operatorname{Pr}=6.2, M_{n}=1.0, \phi=0.1, \mathrm{Nr}=0.3, A^{*}=0.03, B^{*}=0.03$, $L=1.0$, and $S=0.5$.

increase in nanosolid volume fraction. This is because thermal conductivity of the nanoparticles in the base fluid raises the temperature of the nanofluid in the case of Ag-Water.

Figure 4 is plotted to show the effect of slip parameter on the velocity and temperature profiles. It is evident that the velocity profile of the nanofluid increases as the slip parameter decreases. When slip occurs, the flow velocity near the sheet will not be equal to the stretching velocity of the sheet. With the increase in slip parameter, such slip velocity increases and consequently nanofluid velocity decreases, because under the slip condition, the pulling of the stretching sheet can only be partly transmitted to the nanofluid. Further, this leads to decrease in the thickness of momentum boundary layer. As the slip parameter increases, the thermal boundary layer increases. This means that the partial slip parameter leads to thickening of the thermal boundary layer.

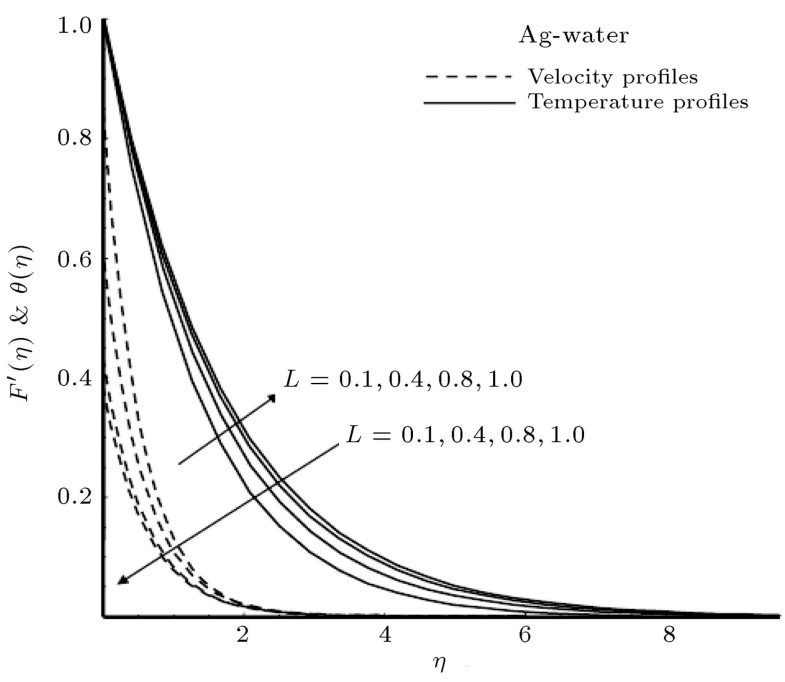

Figure 4. Effect of the slip parameter on velocity and temperature distributions with $\operatorname{Pr}=6.2, M_{n}=1.0$, $\phi=0.1, \mathrm{Nr}=0.3, S=0.5, A^{*}=0.03$, and $B^{*}=0.03$. 


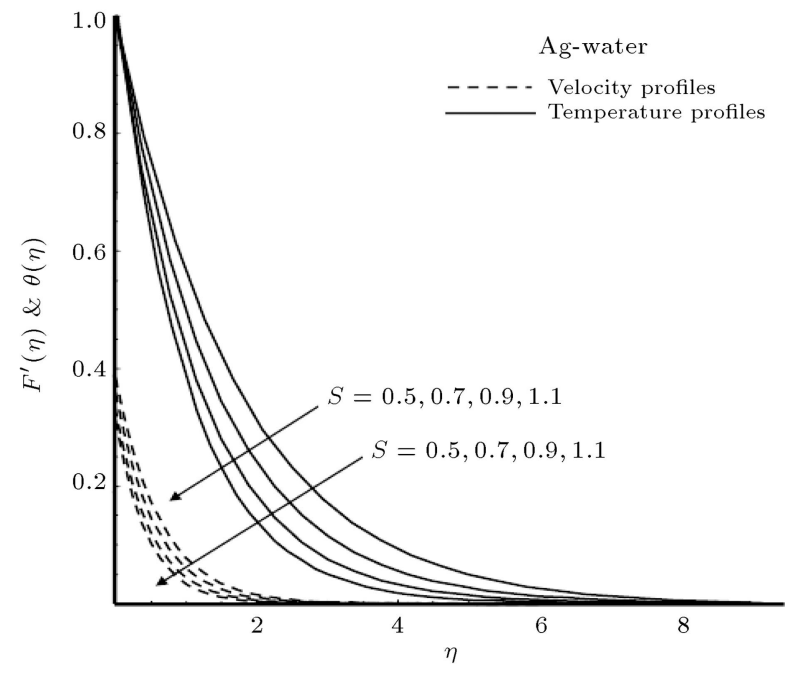

Figure 5. Effect of suction parameter on velocity and temperature distributions with $\operatorname{Pr}=6.2, M_{n}=1.0$, $\phi=0.1, \mathrm{Nr}=0.3, L=1.0, A^{*}=0.03$, and $B^{*}=0.03$.

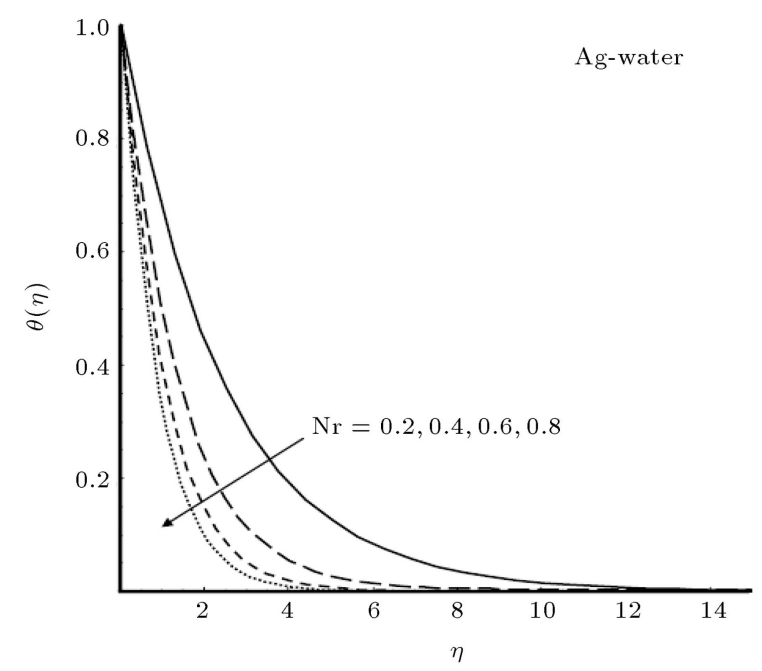

Figure 6. Effect of radiation parameter on temperature distributions with $\operatorname{Pr}=6.2, M_{n}=1.0, \phi=0.1, L=1.0$, $S=0.5, A^{*}=0.03$, and $B^{*}=0.03$.

The effect of suction parameter on velocity and temperature profiles is demonstrated in Figure 5. The effect of suction parameter slows down the velocity of the nanofluid. The boundary layer thickness decreases as suction parameter increases. As suction parameter increases, temperature decreases, which elucidates the fact that the effect of suction parameter reduces the temperature profile.

Figure 6 shows the effect of radiation parameter on the temperature profile. It is evident that the temperature decreases as the radiation parameter increases. This result qualitatively agrees with expectations, since the effect of radiation is to decrease the rate of energy transport to the nanofluid, thereby decreasing temperature of the nanofluid.

Figures 7 and 8 present the effects of space-

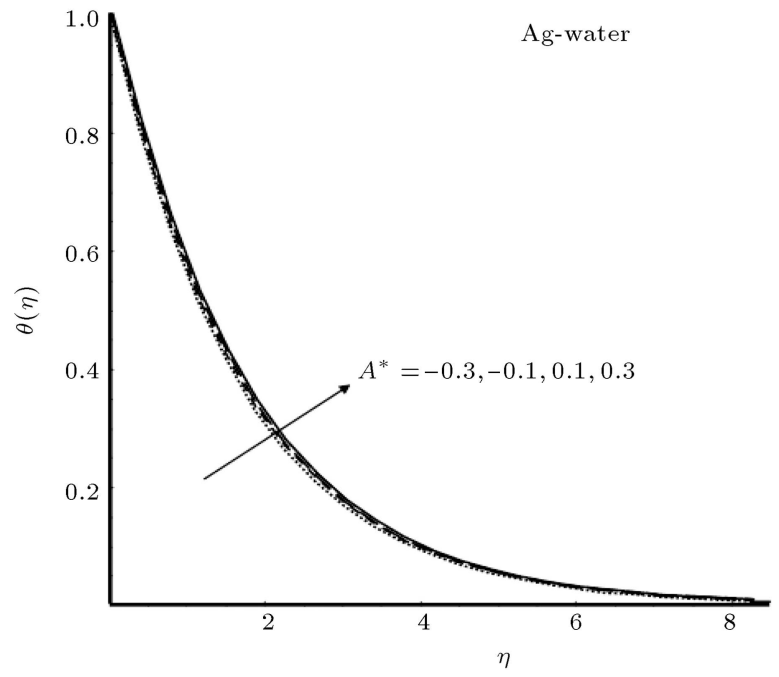

Figure 7. Effect of non-uniform heat source/sink parameter $\left(A^{*}\right)$ on temperature distribution with $\operatorname{Pr}=6.2, M_{n}=1.0, \phi=0.1, \mathrm{Nr}=0.3, L=1.0, S=0.5$, and $B^{*}=0.03$.

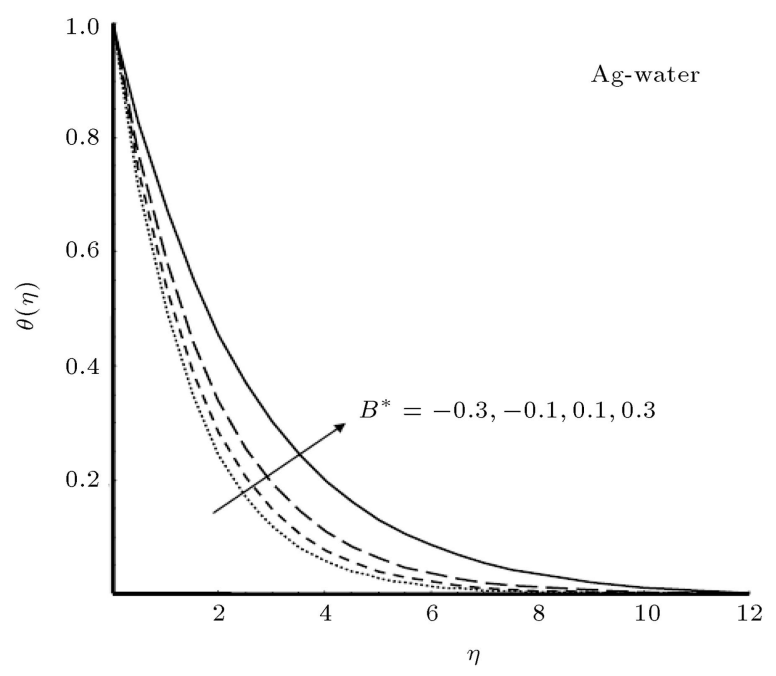

Figure 8. Effect of the non-uniform heat source/sink parameter $\left(B^{*}\right)$ on temperature distribution with $\operatorname{Pr}=6.2, M_{n}=1.0, \phi=0.1, \mathrm{Nr}=0.3, L=1.0, S=0.5$, and $A^{*}=0.03$.

dependent and temperature-dependent heat source/ sink parameters $A^{*}$ and $B^{*}$, respectively, on the temperature profile of Ag-water. Figure 7 shows that temperature profile increases with the increasing values of $A^{*}$. This is because with an increase in the value of $A^{*}>0$ (heat source), the boundary layer generates energy, which causes the temperature profile to increase; whereas in the case of $A^{*}<0$ (absorption), the boundary layer absorbs energy causing temperature of the nanofluid to decrease. Figure 8 illustrates that the temperature profile increases with increase in the values of the temperature-dependent heat source/sink parameter $B^{*}$ in the Ag-water. Thus, energy is released when $B^{*}>0$, which causes the 


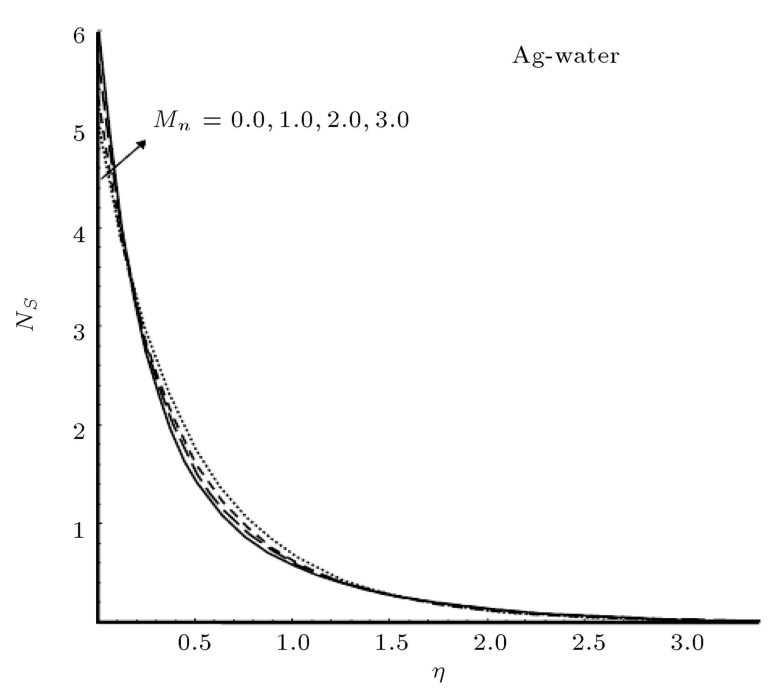

Figure 9. Effect of magnetic parameter on entropy generation with $\operatorname{Pr}=6.2, \phi=0.1, \mathrm{Nr}=0.3, L=0.1$, $S=0.5, A^{*}=0.1, B^{*}=0.1, \operatorname{Br} \Omega^{-1}=1.0, \operatorname{Re}_{x}=1.0$, and $\mathrm{Ha}=1.0$.

temperature of the nanofluid to increase; whereas when the energy is absorbed by decreasing values of $B^{*}<0$, the temperature significantly drops near the boundary layer.

The influence of the magnetic parameter on the entropy generation number is shown in Figure 9. It can be seen that the entropy generation increases with the increasing values of magnetic parameter. Entropy generation is intensified near the wall at which the magnetic parameter causes higher dissipation energy. Also, as the magnetic parameter increases, the entropy generation near the wall increases, while the entropy generation far from the wall is not affected seriously. The reason for this phenomenon is that increasing the magnetic parameter causes the resistant forces against the fluid movement and then, heat transfer rate in the boundary layer increases.

Figure 10 indicates the effect of the nanosolid volume fraction on the entropy generation number. It is evident that the entropy generation number decreases with the increase in the nanosolid volume fraction, due to the higher dissipation energy resulted from the sharper velocity gradient near the wall, and an opposite trend is observed far away from the wall. Figure 11 displays the effect of radiation parameter on entropy generation. The figure reveals that entropy considerably increases with the increasing values of radiation parameter. The increase in entropy generation is due to the increase in the emission rate of radiation near the wall and an opposite trend is observed away from the wall.

Figures 12 and 13 display the effect of nonuniform heat source/sink parameter on the entropy generation parameter. It can be seen that the entropy generation decreases in the case of heat source (i.e.,

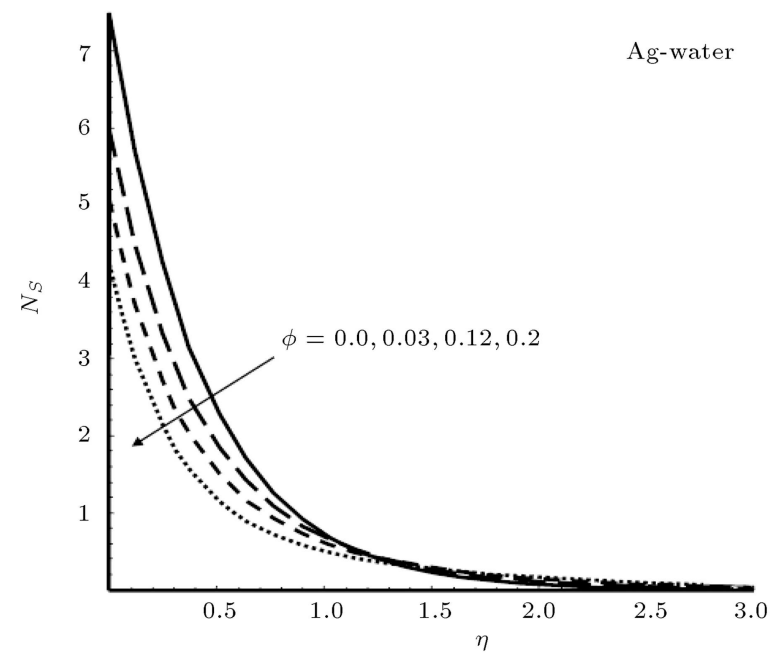

Figure 10. Effect of nanoparticles volume fraction parameter on entropy generation with $\operatorname{Pr}=6.2, M_{n}=1.0$, $\mathrm{Nr}=0.3, L=0.1, S=0.5, A^{*}=0.1, B^{*}=0.1$, $\mathrm{Br} \Omega^{-1}=1.0, \operatorname{Re}_{x}=1.0$, and $\mathrm{Ha}=1.0$.

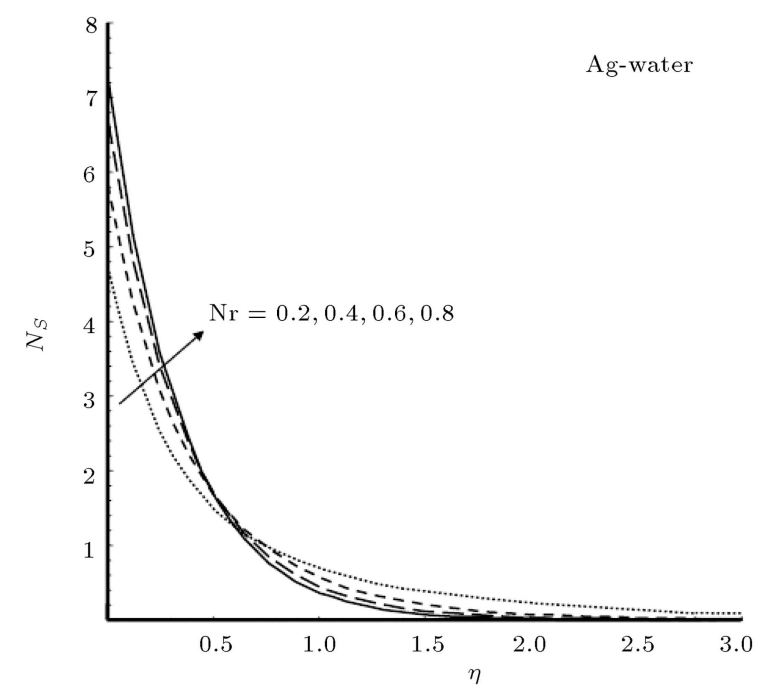

Figure 11. Effect of radiation parameter on entropy generation with $\operatorname{Pr}=6.2, M_{n}=1.0, \phi=0.1, L=0.1$, $S=0.5, A^{*}=0.1, B^{*}=0.1, \operatorname{Br} \Omega^{-1}=1.0, \operatorname{Re}_{x}=1.0$, and $\mathrm{Ha}=1.0$.

$A^{*}>0$ and $B^{*}>0$ ). It shows that heat source dominates the entropy generation in nanofluid, whereas in the case of heat sink (i.e. $A^{*}<0$ and $B^{*}<0$ ), it produces more entropy in nanofluid.

Figure 14 illustrates the effect of slip parameter on the entropy generation number. It is noticed that entropy generation increases as the slip parameter decreases. Figure 15 displays the effect of suction parameter on entropy generation. It is observed that suction parameter augments the entropy generation; thus, suction parameter creates more entropy in nanofluid.

Figure 16 demonstrates the influence of different nanoparticles such as Copper $(\mathrm{Cu})$, Silver $(\mathrm{Ag})$, 


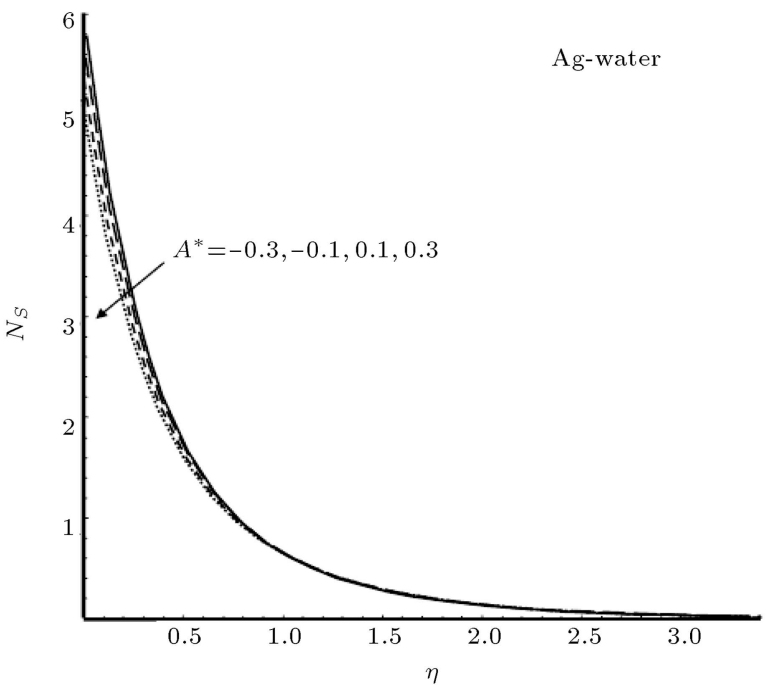

Figure 12. Effect of non-uniform heat source/sink parameter $\left(A^{*}\right)$ on entropy generation with $\operatorname{Pr}=6.2$, $M_{n}=1.0, \phi=0.1, \mathrm{Nr}=0.3, L=0.1, S=0.5, B^{*}=0.1$, $\mathrm{Br} \Omega^{-1}=1.0, \operatorname{Re}_{x}=1.0$, and $\mathrm{Ha}=1.0$.

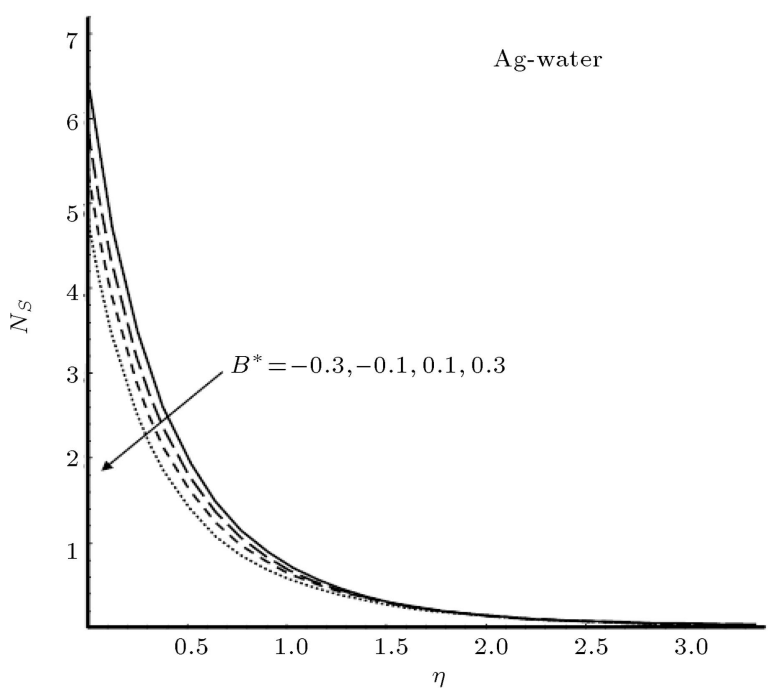

Figure 13. Effect of non-uniform heat source/sink parameter $\left(B^{*}\right)$ on entropy generation with $\operatorname{Pr}=6.2$, $M_{n}=1.0, \phi=0.1, \mathrm{Nr}=0.3, L=0.1, S=0.5, A^{*}=0.1$, $\mathrm{Br} \Omega^{-1}=1.0, \operatorname{Re}_{x}=1.0$, and $\mathrm{Ha}=1.0$.

Alumina $\left(\mathrm{Al}_{2} \mathrm{O}_{3}\right)$, and Titanium Oxide $\left(\mathrm{TiO}_{2}\right)$ on the velocity, temperature, and entropy generation profiles, respectively. Figure 16(a) exhibits the velocity distribution for the nanoparticles $\mathrm{Cu}, \mathrm{Ag}, \mathrm{Al}_{2} \mathrm{O}_{3}$, and $\mathrm{TiO}_{2}$. It can be seen that the velocity profile is higher for $\mathrm{TiO}_{2}$-water and lower for Ag-water. Highdensity nanoparticles have very low velocity. From Figure 16(b), it is noted that the temperature profile is higher for $\mathrm{Ag}$-water and lower for $\mathrm{TiO}_{2}$-water. It is clear that the Ag-water has high rate of heat transfer compared to other nanoparticles. This is due to the fact that the thermal conductivity of the Ag-water is very high compared to other nanoparticles. This

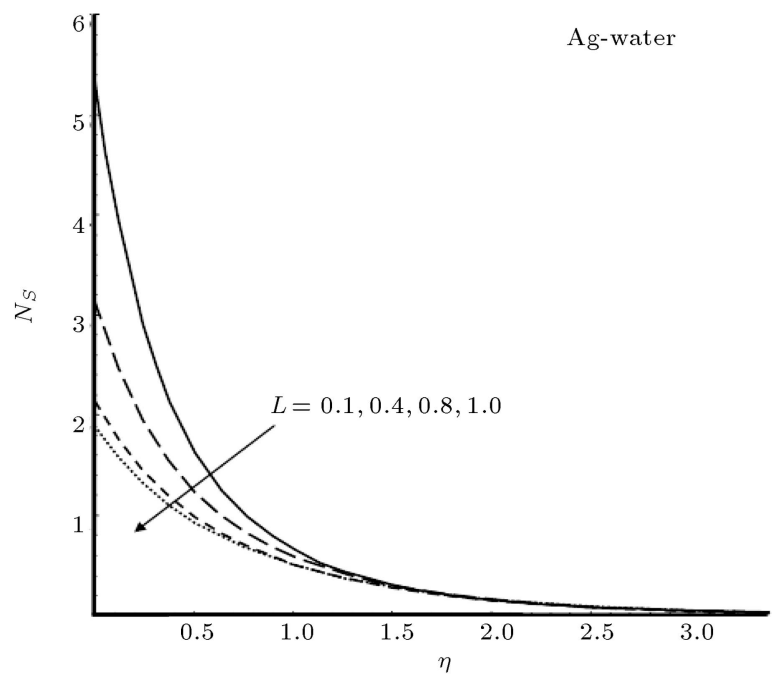

Figure 14. Effect of slip parameter on entropy generation with $\operatorname{Pr}=6.2, M_{n}=1.0, \phi=0.1, \mathrm{Nr}=0.3, S=0.5$, $A^{*}=0.1, B^{*}=0.1, \operatorname{Br} \Omega^{-1}=1.0, \operatorname{Re}_{x}=1.0$, and $\mathrm{Ha}=1.0$.

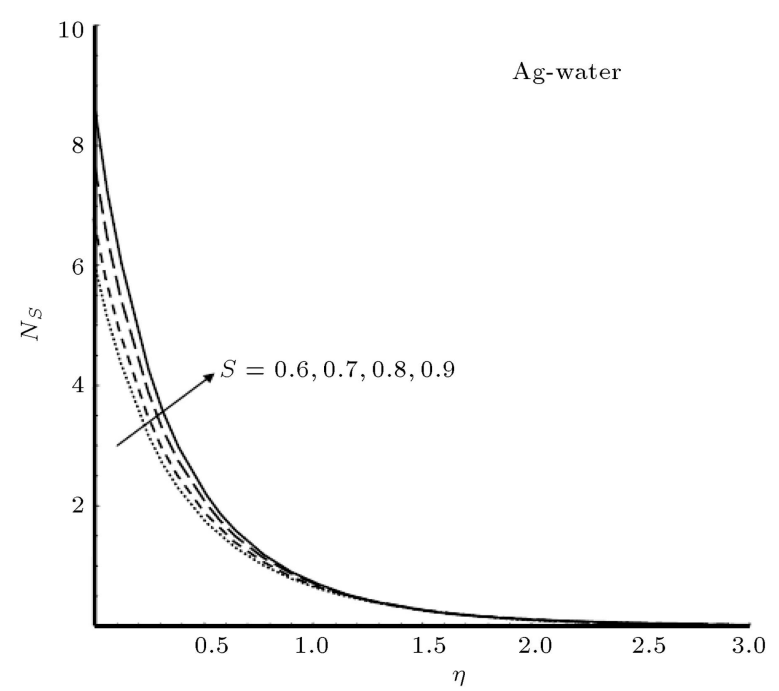

Figure 15. Effect of suction parameter on entropy generation with $\operatorname{Pr}=6.2, M_{n}=1.0, \phi=0.1, \mathrm{Nr}=0.3$, $L=0.1, A^{*}=0.1, B^{*}=0.1, \operatorname{Br} \Omega^{-1}=1.0, \operatorname{Re}_{x}=1.0$, and На $=1.0$.

shows that thermal conductivity of the nanoparticles also affects the temperature of the nanoparticle. From Figure 16(c), it is clear that the entropy generation number is maximum for Ag-water and minimum for $\mathrm{TiO}_{2}$-water. The entropy generation number of $\mathrm{Al}_{2} \mathrm{O}_{3^{-}}$ water is greater than that of $\mathrm{Cu}$-water. The entropy generation is higher for the metallic nanofluids and is lower for the non-metallic nanofluids.

Figure 17 shows the effects of slip, magnetic, and nanosolid volume fraction parameters on local skin friction coefficient. It is clear that $-F^{\prime \prime}(0)$ values decrease with slip parameter and increase with magnetic and nanoparticle volume fraction parameters. The values 


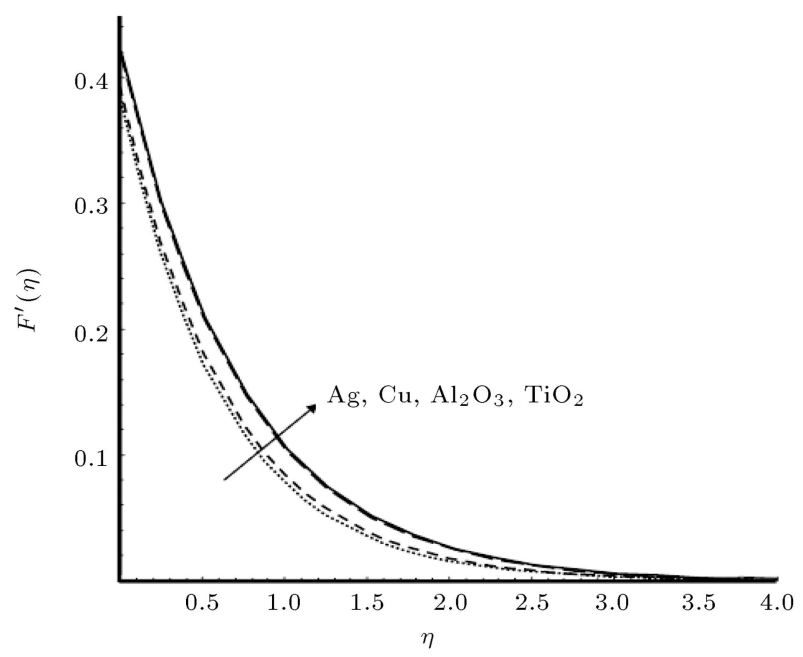

Figure 16(a). Effect of different nanofluids on velocity distribution with $\operatorname{Pr}=6.2, M_{n}=1.0, \phi=0.1, L=1.0$, and $S=0.5$.

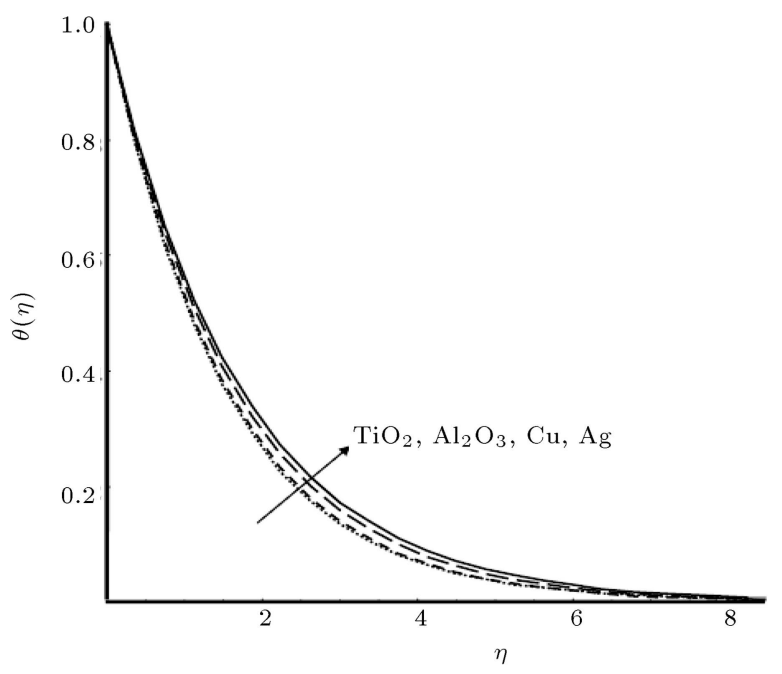

Figure 16(b). Effect of different nanofluids on temperature distribution with $\operatorname{Pr}=6.2, M_{n}=1.0$, $\phi=0.1, \mathrm{Nr}=0.3, L=1.0, S=0.5, A^{*}=0.03$, and $B^{*}=0.03$.

of reduced Nusselt number are plotted in Figures 18(a) and $18(\mathrm{~b})$. The reduced Nusselt number decreases with the increasing values of magnetic, slip, and nanoparticle volume fraction parameters (Figure 18(a)). It is observed from Figure 18(b) that $-\theta^{\prime}(0)$ increases in the case of heat source and decreases in heat sink case; also, it increases with the increasing values of radiation parameter.

\section{Conclusion}

The present study gives the analytical and numerical solutions for entropy generation analysis of hydromagnetic slip flow of an incompressible viscous nanofluid (Cu-water, Ag-water, $\mathrm{Al}_{2} \mathrm{O}_{3}$-water, and $\mathrm{TiO}_{2}$-water) over a stretching sheet in the presence of thermal ra-

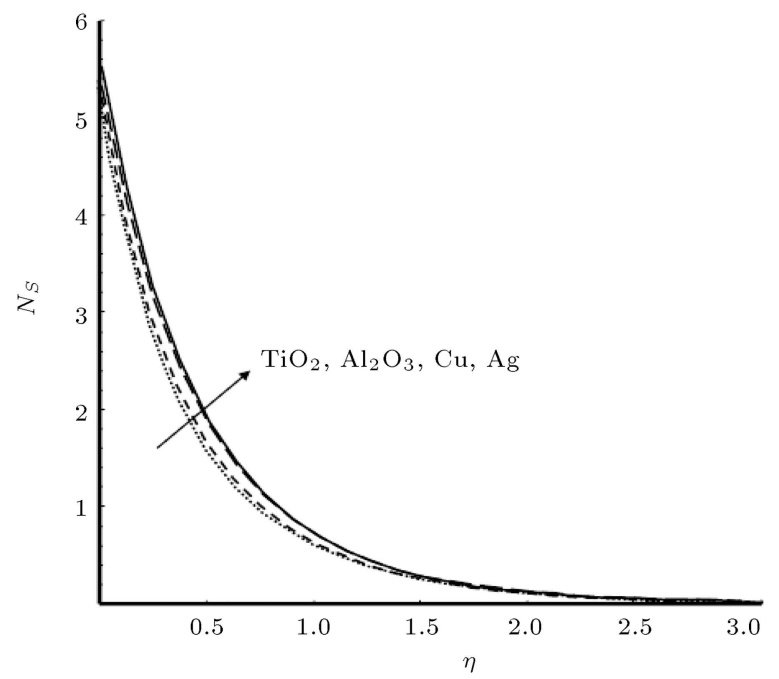

Figure 16(c). Effect of different nanoparticles on entropy generation with $\operatorname{Pr}=6.2, M_{n}=1.0, \phi=0.1, \mathrm{Nr}=0.3$, $L=0.1, A^{*}=0.1, B^{*}=0.1, \operatorname{Br} \Omega^{-1}=1.0, S=0.5$, $\mathrm{Re}_{x}=1.0$, and $\mathrm{Ha}=1.0$.

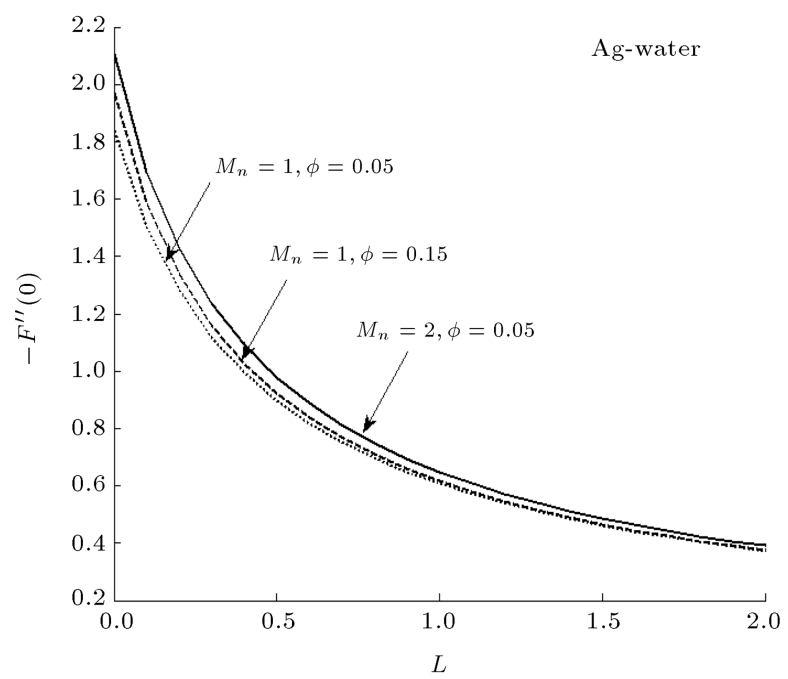

Figure 17. Effect of nanoparticles volume fraction, slip and magnetic parameters on local skin friction coefficient with $\operatorname{Pr}=6.2$ and $S=0.5$.

diation and investigates non-uniform heat source/sink. The partial differential equations governing the problem under consideration are transformed by Lie symmetry group of transformations into a system of ordinary differential equations which are solved analytically using hypergeometric functions and numerically by Runge-Kutta-Gill method with shooting technique which is used to compute the entropy generation number. The main conclusions derived from this study are as follows.

- The velocity of the nanofluid decreases with increase in magnetic parameter, nanosolid volume fraction parameter, slip parameter, and suction parameter;

- The temperature of the nanofluid increases with 


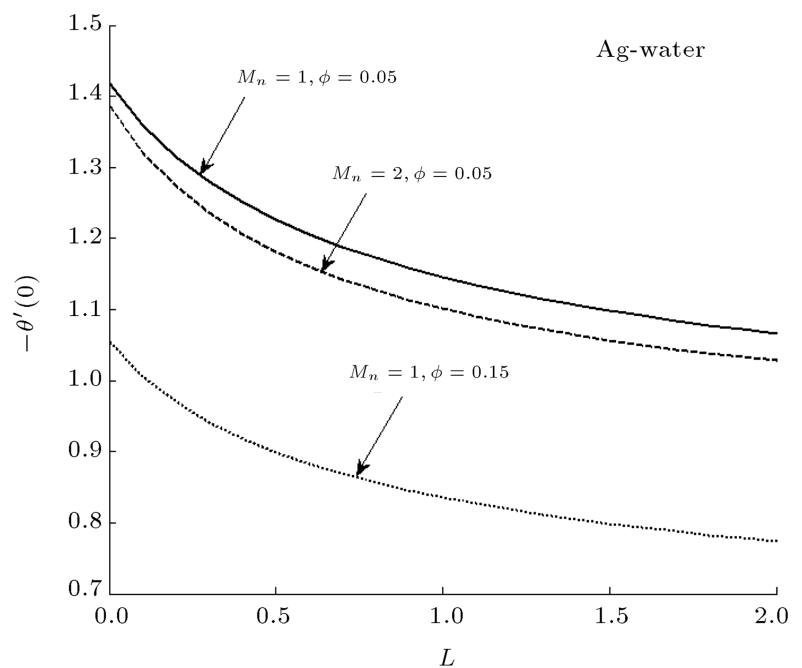

Figure 18(a). Effect of nanoparticles volume fraction, slip and magnetic parameters on reduced Nusselt number with $\mathrm{Pr}=6.2, \mathrm{Nr}=0.7, S=0.5, A^{*}=0.03$, and $B^{*}=0.03$.

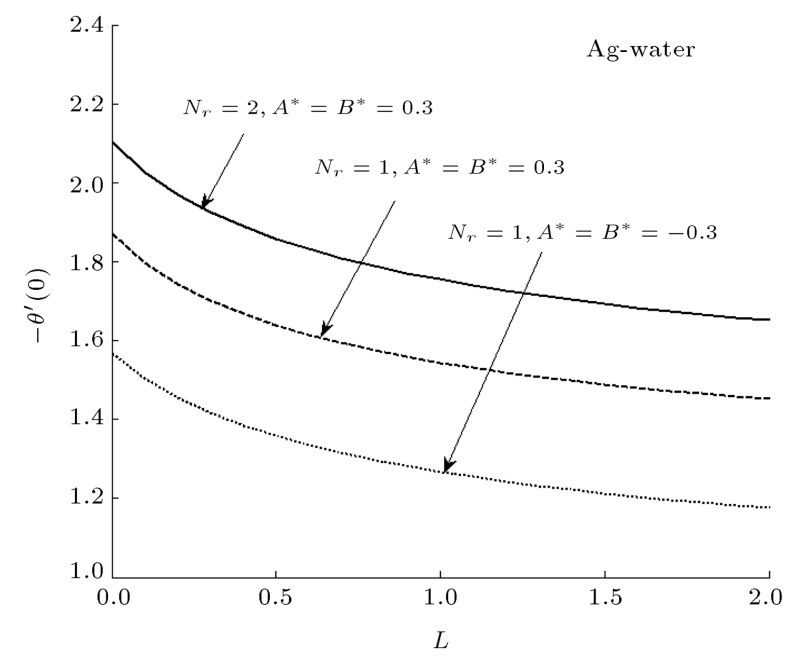

Figure 18(b). Effect of radiation and non-uniform heat source/sink parameters on reduced Nusselt number with $\operatorname{Pr}=6.2, S=0.5, M_{n}=1$, and $\phi=0.05$.

the increasing values of magnetic parameter, nanosolid volume fraction parameter, non-uniform heat source/sink parameters, and slip parameter. The temperature of the nanofluid increases with the decreasing values of radiation parameter and suction parameter;

- The increasing values of magnetic parameter, radiation parameter, and suction parameter increase the generation of entropy in the nanofluid flow field. The entropy generation increases with decrease in slip parameter and non-uniform heat source parameter. The rising values of nanosolid volume fraction parameter decrease the entropy generation near the wall, and an opposite trend is observed far away from the wall;
- Ag-water fluid considerably decreases velocity and increases temperature compared to other nanofluids, viz. $\mathrm{Cu}, \mathrm{Al}_{2} \mathrm{O}_{3}$, and $\mathrm{TiO}_{2}$. The entropy generation is higher for metallic and lower for non-metallic nanoparticles in the base fluid. The presence of metallic nanoparticles creates more entropy in the nanofluid flow than the non-metallic nanoparticles.

\section{Nomenclature}

\begin{tabular}{|c|c|}
\hline$A^{*}$ & $\begin{array}{l}\text { Space dependent internal heat } \\
\text { source/sink parameter }\end{array}$ \\
\hline$B^{*}$ & $\begin{array}{l}\text { Temperature dependent internal heat } \\
\text { source/sink parameter }\end{array}$ \\
\hline$B_{0}$ & Magnetic field strength \\
\hline $\mathrm{Br}$ & Brinkman number \\
\hline $\mathrm{Ha}$ & Hartmann number \\
\hline$L$ & Partial slip parameter \\
\hline$M$ & Kummer's function \\
\hline$M_{n}$ & Magnetic parameter \\
\hline$N_{r}$ & Radiation parameter \\
\hline$N_{s}$ & Entropy generation number \\
\hline $\operatorname{Pr}$ & Prandtl number \\
\hline $\operatorname{Re}_{x}^{1 / 2} C_{f}$ & Local skin friction coefficient \\
\hline $\operatorname{Re}_{x}^{-1 / 2} \mathrm{Nu}_{x}$ & Reduced Nusselt number \\
\hline$S_{G}$ & $\begin{array}{l}\text { Local volumetric entropy generation } \\
\text { rate }\end{array}$ \\
\hline$\left(S_{G}\right)_{0}$ & Characteristic entropy generation rate \\
\hline$T$ & Local temperature of the fluid \\
\hline$k_{n f}$ & Thermal conductivity of the nanofluid \\
\hline$k_{f}$ & Thermal conductivity of the base fluid \\
\hline$k_{s}$ & $\begin{array}{l}\text { Thermal conductivity of the } \\
\text { nanoparticles }\end{array}$ \\
\hline$\sigma$ & Electric conductivity \\
\hline$\Omega$ & Dimensionless temperature difference \\
\hline$\phi$ & The solid volume fraction \\
\hline$\rho_{n f}$ & The effective density of the nanofluid \\
\hline$\rho_{f}$ & Density of the pure fluid \\
\hline$\rho_{s}$ & Density of the nanoparticles \\
\hline$\mu_{n f}$ & $\begin{array}{l}\text { Effective dynamic viscosity of the } \\
\text { nanofluid }\end{array}$ \\
\hline$\mu_{f}$ & Dynamic viscosity of the basic fluid \\
\hline$\eta$ & Space variable \\
\hline$n f$ & Thermal diffusivity of the nanofluid \\
\hline
\end{tabular}

\section{References}

1. Choi, S.U.S. and Eastman, J.A. "Enhancing thermal conductivity of fluids with nanoparticles", Mater. Sci., 231, pp. 99-105 (1995). 
2. Eastman, J.A., Choi, U.S., Li, S., Soyez, G., Thompson, L.J. and DiMelfi, R.J. "Novel thermal properties of nanostructured materials", Mater. Sci. Forum., pp. 629-634 (1999).

3. Xuana, Y. and Roetzel, W. "Conceptions for heat transfer correlation of nanofluids", Int. J. Heat Mass Transfer, 43, pp. 3701-3707 (2000).

4. Masuda, H., Ebata, A., Teramae, K. and Hishinuma, H. "Alteration of thermal conductivity and viscosity of liquid by dispersing ultra-fine particles (Dispersion of 7- $\mathrm{A}_{2} \mathrm{O}_{3}, \mathrm{SiO}_{2}$ and $\mathrm{TiO}_{2}$ ultra-fine particles)", Netsu. Bussei., 4, pp. 227-233(1993).

5. Kakac, S. and Pramuanjaroenkij, A. "Review of convective heat transfer enhancement with nanofluids", Int. J. Heat Mass Transfer, 52, pp. 3187- 3196 (2009).

6. Nadeem, S., Haq, R.U. and Khan, Z.H. "Heat transfer analysis of water based nanofluid over an exponentially stretching sheet", Alexandria Eng. J., 53, pp. 219-224 (2014).

7. Hatami, M. and Ganji, D.D. "Natural convection of sodiumalginate(SA) non-Newtonian nanofluid flow between two vertical flat plates by analytical and numerical methods", Case Stud. Therm. Eng., 2, pp. 14-22 (2014).

8. Abed, A.M., Sopian, K., Mohammedc, H.A., Alghoul, M.A., Ruslan, M.H., Sohif, M. and Al-Shamani, A.N. "Enhance heat transfer in the channel with V-shaped wavy lower plate using liquid nanofluids", Case Stud. Therm. Eng., 5, pp. 13-23 (2015).

9. Rashidi, M.M., Rostami, B., Freidoonimehr, N. and Abbasbandey, S. "Free convective heat and mass transfer for MHD fluid flow over a permeable vertical stretching sheet in the presence of the radiation and buoyancy effects", Ain Shams Engineering Journal, 5, pp. 901-912 (2014).

10. Rashidi, M.M. and Keimanesh, K. "Using differential transform method and pad approximant for solving MHD flow in a laminar liquid film from a horizontal stretching surface", Mathematical Problems in Engineering, Article ID 491319 (2010).

11. Rashidi, M.M., Vishnu Ganesh, N., Abdul Hakeem, A.K. and Ganga, B. "Buoyancy effect on MHD flow of nanofluid over a stretching sheet in the presence of thermal radiation", J. Mol. Liq., 198, pp. 234-238 (2014).

12. Hamad, M.A.A. "Analytical solution of natural convection flow of a nanofluid over a linearly stretching sheet in the presence of magnetic field", Int. Comm. Heat Mass Transfer, 38, pp. 487-492 (2011).

13. Vishnu Ganesh, N., Ganga, B. and Abdul Hakeem, A.K. "Lie symmetry group analysis of magnetic field effects on free convective flow of a nanofluid over a semi-infinite stretching sheet", J. Egyptian Math. Soc., 22, pp. 304-310 (2014).

14. Vishnu Ganesh, N., Abdul Hakeem, A.K., Jayap- rakash, R. and Ganga, B. "Analytical and numerical studies on hydromagnetic flow of water based metal nanofluids over a stretching sheet with thermal radiation effect", J. Nanofluids, 3, pp. 1-8 (2014).

15. Rashidi, M.M., Kavyani, N. and Abelman, S. "Investigation of entropy generation in MHD and slip flow over a rotating porous disk with variable properties", Int. J. Heat Mass Transfer, 70, pp. 892-917 (2014).

16. Rashidi, M.M. and Erfani, E. "Analytical method for solving steady MHD convective and slip flow due to a rotating disk with viscous dissipation and ohmic heating", Engineering Computations, 29(6), pp. 562579 (2012).

17. Abdul Hakeem, A.K., Kalaivanan, R., Vishnu Ganesh, N. and Ganga, B. "Effect of partial slip on hydromagnetic flow over a porous stretching sheet with nonuniform heat source/sink, thermal radiation and wall mass transfer", Ain Shams Eng. J., 5, pp. 913-922 (2014).

18. Das, K. "Slip flow and convective heat transfer of nanofluids over a permeable stretching surface", Comput. Fluids, 64, pp. 34-42 (2012).

19. Turkyilmazoglu, M. "Exact analytical solutions for heat and mass transfer of MHD slip flow in nanofluids"', Chem. Eng. Sci., 84, pp. 182-187 (2012).

20. Noghrehabad, A. and Pourrajab, R. "Effect of partial slip boundary condi- tion on the flow and heat transfer of nanofluids past stretching sheet prescribed constant wall temperature", Int. J. Therm. Sci., 54, pp. 253261 (2012).

21. Ibrahim, W. and Shankar, B. "MHD boundary layer flow and heat transfer of a nanofluid past a permeable stretching sheet with velocity, thermal and solutal slip boundary conditions", Comput. Fluids, 75, pp. 1-10 (2013).

22. Abdul Hakeem, A.K., Vishnu Ganesh, N. and Ganga, B. "Magnetic field effect on second order slip flow of nanofluid over a stretching/shrinking sheet with thermal radiation effect", J. Magn. Magn. Mater., 381, pp. 243-257 (2015).

23. Aboud, S. and Saouli, S. "Entropy analysis for viscoelastic magnetohydro- dynamic flow over a stretching surface", Int. J. Non-linear Mech., 45, pp. 482-489 (2010).

24. Bejan, A., Entropy Generation Minimization, CRC Press, Boca Raton, New York (1996).

25. Sohel, M.R., Saidur, R., Hassan, N.H., Elias, M.M., Khaleduzzaman, S.S. and Mahbubul, I.M. "Analysis of entropy generation using nanofluid flow through the circular micro channel and minichannel heat sink", Int. Comm. Heat Mass Transfer, 46, pp. 85-91 (2013).

26. Moghaddami, M., Shahidi, S. and Siavashi, M. "Entropy generation analysis of nanofluid flow in turbulent and laminar regimes", J. Comput. Theor. Nanosci., 9, pp. 1586-1595 (2012). 
27. Shahi, M., Mahmoudi, A.H. and Raouf, A.H. "Entropy generation due to natural convection cooling of a nanofluid", Int. Comm. Heat Mass Transfer, 38, pp. 972-983 (2011).

28. Mahian, O., Mahmud, S. and Heris, S.Z. "Analysis of entropy generation between co-rotating cylinders using nanofluids", Energy, 44, pp. 438-446 (2012).

29. Mahian, O., Pop, I., Sahin, A.Z., Oztop, H.F. and Wongwises, S. "Irreversibility analysis of a vertical annulus using $\mathrm{TiO}_{2} /$ water nanofluid with MHD flow effects", Int. J. Heat Mass Transfer, 64, pp. 671-679 (2013).

30. Malvandi, A., Ganji, D.D., Hedayati, F. and Yousefi Rad, E. "An analytical study on entropy generation of nanofluids over a flat plate", Alexandria Eng. J., 52, pp. 595-604 (2013).

31. Noghrehabadi, A., Saffarian, M.R., Pourrajab, R. and Ghalambaz, M. "Entropy analysis for nanofluid flow over a stretching sheet in the presence of heat generation/absorption and partial slip", J. Mech. Sci. Technol., 27, pp. 927-937 (2013).

32. Butt, A.S., Munawar, S., Ali, A. and Mehmood, A. "Entropy generation in hydrodynamic slip flow over a vertical plate with convective boundary", J. Mech. Sci. Technol., 26, pp. 2977-2984 (2012).

33. Govindaraju, M., Vishnu Ganesh, N., Ganga, B. and Abdul Hakeem, A.K. "Entropy generation analysis of magneto hydrodynamic flow of a nanofluid over a stretching sheet", J. Egyptian Math. Soc., 23, pp. 429434 (2015).

34. Abel, M.S. and Nandeppanavar, M.M. "Heat transfer in a MHD viscoelastic boundary layer flow over a stretching with nonuniform heat source/sink", Commun. Nonlinear Sci. Numer. Simul., 14, pp. 2120-2131 (2009).

35. Abdul Hakeem, A.K. and Sathiyanathan, K. "An analytic solution of an oscillatory flow through a porous medium with radiation effect", Nonlinear Anal.: Hybrid Syst., 3, pp. 288-295 (2009).

36. Abdul Hakeem, A.K., Vishnu Ganesh, N. and Ganga, B. "Effect of heat radiation in a Walter's liquid B fluid over a stretching sheet with non-uniform heat source/sink and elastic deformation", J. King Saud University-Eng. Sci., 26, pp. 168-175 (2014).

37. Anjali Devi, S.P. and Ganga, B. "Viscous dissipation effects on nonlinear MHD flow in a porous medium over a stretching porous surface", Int. J. of Appl. Math. and Mech., 5, pp. 45-59 (2009).

38. Woods, L.C., Thermodynamics of Fluid Systems, Oxford University Press, Oxford (1975).

39. Arpaci, V.S. "Radiative entropy production-lost heat into entropy", Int. J. Heat Mass Transfer, 30, pp. 2115-2123 (1987).
40. Paresh, V. and Archana, R. "Entropy regime for radiative MHD coquette flow inside a channel with naturally permeable base", Int. J. Energy and Technol., 5, pp. 1-9 (2013).

41. Wang, C.Y. "Free convection on a vertical stretching surface", J. Appl. Math. Mech. (ZAMM), 69, pp. 418420 (1989).

\section{Biographies}

Abdul Kaffoor Abdul Hakeem was born and brought up in the district of Coimbatore, Tamil Nadu, India. He obtained MPhil and PhD degrees in Mathematics from Bharathiar University, Coimbatore. He is currently working as an Assistant Professor in the Department of Mathematics, Sri Ramakrishna Mission Vidhyalaya College of Arts and Science, Coimbatore, affiliated to Bharathiar University. Besides teaching, he is actively engaged in the field of fluid mechanics, particularly in heat transfer in cavities, boundary layer flows, nanofluid flow through porous media, and slip flow model.

Mathialagan Govindaraju works as an Assistant Professor in the Department of Mathematics, Sri Ramakrishna Mission Vidhyalaya College of Arts and Science, Coimbatore Tamilnadu, India. He received his MPhil degree in Mathematics from Bharathiar University, Coimbatore. Nowadays, he is doing his research under the guidance of Dr. A. K. Abdul Hakeem.

Bhose Ganga was born and brought up in the district of Nilgiris, Tamil Nadu, India. She obtained MPhil and $\mathrm{PhD}$ degrees in Mathematics from Bharathiar University, Coimbatore. She is currently working as an Assistant Professor in the Department of Mathematics, Providence College for Women, Coonoor, affiliated to Bharathiar University. Besides teaching, she is actively engaged in research in the field of fluid mechanics, particularly in boundary layer flows, nanofluid flow through porous media, and slip flow model.

Marimuthu Kayalvizhi works as an Assistant Professor in Mathematics at Sathyabama University, Chennai, India. She obtained MPhil and PhD degrees in Mathematics from Bharathiar University, Coimbatore. Besides teaching, she is actively engaged in research in the field of fluid mechanics, particularly in heat mass transfer, boundary layer flows, and nanofluid. 